\title{
Socioeconomic position and consumption of sugary drinks, sugar-sweetened beverages and $100 \%$ juice among Canadians: a cross-sectional analysis of the 2015 Canadian Community Health Survey-Nutrition
}

\author{
Christine Warren ${ }^{1}$ - Erin Hobin ${ }^{1,2,3}$. Douglas G. Manuel ${ }^{4,5,6,7,8}$. Laura N. Anderson ${ }^{9,10}$ • David Hammond ${ }^{11}$. \\ Mahsa Jessri ${ }^{12} \cdot$ JoAnne Arcand ${ }^{13} \cdot$ Mary L'Abbé $^{2} \cdot$ Ye Li $^{1,3} \cdot$ Laura C. Rosella $^{3,5,14,15,16} \cdot$ Heather Manson $^{3}$. \\ Brendan T. Smith ${ }^{1,3}$ (])
}

Received: 12 July 2021 / Accepted: 7 December 2021 / Published online: 9 February 2022

(c) Crown 2022

\begin{abstract}
Objective The aim of this study was to describe sugary drink (beverages with free sugars), sugar-sweetened beverage (beverages with added sugars, SSB) and 100\% juice (beverages with natural sugars) consumption across socioeconomic position (SEP) among Canadians.

Methods We conducted a cross-sectional analysis of 19,742 respondents of single-day 24-h dietary recalls in the nationally representative 2015 Canadian Community Health Survey-Nutrition. Poisson regressions were used to estimate the prevalence of consuming each beverage type on a given day. Among consumers on a given day, linear regressions were used to estimate mean energy intake. Models included household education, food security and income quintiles as separate unadjusted exposures. Sex-specific models were estimated separately for children/adolescents (2-18 years) and adults $(19+)$.

Results Among female children/adolescents, the prevalence of consuming sugary drinks and, separately, SSB ranged from 11 to 21 and 8 to 27 percentage-points higher among lower education compared to 'Bachelor degree or above' households. In female adults, the prevalence of consuming sugary drinks and, separately, SSB was 10 (95\% CI: 1, 19) and 14 (95\% CI: 2, 27) percentage-points higher in food insecure compared to secure households. In males, the prevalence of consuming $100 \%$ juice was 9 (95\% CI: - 18,0) percentage-points lower among food insecure compared to secure households. Social inequities in energy intake were observed in female adult consumers, among whom mean energy from sugary drinks was $27 \mathrm{kcal}$ (95\% CI: 3, 51) higher among food insecure compared to secure and $35 \mathrm{kcal}(95 \% \mathrm{CI}: 2,67)$ higher from $100 \%$ juice among 'less than high school' education compared to 'Bachelor degree or above' households.

Conclusion Social inequities in sugary drink consumption exist in Canada. The associations differed by SEP indicator. Equitable interventions to reduce consumption are warranted.
\end{abstract}

\section{Résumé}

Objectif Dresser le portrait de la consommation de boissons sucrées (boissons contenant des sucres libres), de boissons contenant du sucre ajouté et de jus purs à $100 \%$ (boissons contenant des sucres naturels) chez la population canadienne en fonction du statut socioéconomique.

Méthode Nous avons effectué une analyse transversale des rappels alimentaires de 24 heures réalisés par 19742 personnes dans le cadre de l'Enquête sur la santé dans les collectivités canadiennes - Nutrition 2015, laquelle est représentative de la population nationale. Nous avons utilisé la régression de Poisson pour estimer la prévalence de la consommation de chaque type de boisson durant un jour donné. Pour calculer l'apport énergétique quotidien moyen, nous avons utilisé des régressions linéaires. Les modèles d'analyse traitent la scolarité, la sécurité alimentaire et les quintiles de revenu des ménages comme des expositions non ajustées distinctes. L'analyse en fonction du sexe est divisée en deux groupes, soit les enfants et adolescents (2 à 18 ans) et les adultes (19 ans et plus).

Extended author information available on the last page of the article 
Résultats Chez les filles et les adolescentes, la prévalence de la consommation de boissons sucrées et de boissons contenant du sucre ajouté est plus élevée (de 11 à 21 points de pourcentage et de 8 à 27 points de pourcentage, respectivement) dans les ménages moins scolarisés que dans les ménages plus scolarisés (baccalauréat et études supérieures). Chez les femmes vivant de l'insécurité alimentaire, la prévalence de la consommation de boissons sucrées et de boissons contenant du sucre ajouté est plus élevée de 10 points de pourcentage (IC de $95 \%: 1,19$ ) et de 14 points de pourcentage (IC de $95 \%: 2,27$ ), respectivement, que chez celles qui n'en vivent pas. Chez les sujets masculins, la prévalence de consommation des jus purs à $100 \%$ est moins élevée de 9 points de pourcentage (IC de $95 \%:-18,0$ ) dans les ménages vivant de l'insécurité alimentaire. Nous avons remarqué des disparités sur le plan social dans l'apport énergétique chez les femmes; l'apport moyen provenant de boissons sucrées est plus élevé de $27 \mathrm{kcal}$ (IC de 95\% : 3, 51) dans les ménages vivant de l'insécurité alimentaire, et l'apport moyen provenant de jus pur à $100 \%$ est plus élevé de $35 \mathrm{kcal}$ (IC de $95 \%: 2,67$ ) dans les ménages moins scolarisés (pas de diplôme d'études secondaires) que chez les ménages plus scolarisés (baccalauréat et études supérieures).

Conclusion Il existe des disparités sur le plan social dans la consommation de boissons sucrées au Canada. Les résultats variaient en fonction de l'indicateur de statut économique. Nous recommandons des interventions équitables pour réduire la consommation de ces boissons.

Keywords 2015 Canadian Community Health Survey-Nutrition · Social inequities · Socioeconomic position · Sugar-containing beverages $\cdot$ Sugary drinks $\cdot$ Sugar-sweetened beverages $\cdot 100 \%$ juice

Mots-clés Enquête sur la santé dans les collectivités canadiennes - Nutrition 2015 - iniquités sociales $\cdot$ statut socioéconomique $\cdot$ boissons contenant du sucre $\cdot$ boissons sucrées $\cdot$ boissons contenant du sucre ajouté $\cdot$ jus pur à $100 \%$

\section{Introduction}

'Sugary drinks', defined as beverages with added sugars ('sugar-sweetened beverages' (SSB)) and beverages with natural intrinsic sugars (100\% juice), contribute to excess dietary sugar intake (World Health Organization (WHO), 2015). Sugary drink consumption is associated with increased risk of obesity, type 2 diabetes, cardiovascular disease, cancer, disability-adjusted life years and mortality (Global Burden of Disease (GBD), 2018; Imamura et al., 2015; Makarem et al., 2018; Malik et al., 2013). Reducing consumption is a primary focus of global nutrition policies, including informational, financial, healthy default choices, and reduced availability interventions (Krieger et al., 2021). For example, the WHO recommends limiting free sugar to less than 10\% of daily energy intake (WHO, 2015). Moreover, Canada's updated 2019 Food Guide advises to 'replace sugary drinks with water', representing a change from the 2007 Canada's Food Guide recommendations which included $100 \%$ juice as a fruit or vegetable serving (Health Canada, 2019b). In addition, Newfoundland and Labrador have included a 20-centper-litre sugary drink tax in the government's proposed 2021-2022 budget, a first for Canada (Coady, 2021). There is a need to implement equitable interventions to reduce sugary drink consumption and associated health risks (Krieger et al., 2021).

In Canada, consumption of traditional sugary drinks (i.e., fruit drinks, regular soft drinks and $100 \%$ juice) has declined by one third between 2004 and 2015 (Czoli et al., 2019; Garriguet, 2019; Jones et al., 2019; Langlois et al., 2019). However, in 2015, sugary drinks contributed an average of
$18 \%$ of total free sugar intake among Canadians (Liu et al., 2020) and were top dietary contributors of Canadians' overall sugar intake across the lifespan (Kirkpatrick et al., 2019; Langlois et al., 2019). Of additional concern, purchases of novel types of SSB (e.g., energy and sport drinks) have increased among Canadians over time (Czoli et al., 2019), reflecting patterns observed in the United States (Drewnowski \& Rehm, 2015; Han \& Powell, 2013). Given the shifting consumption patterns, surveillance of sugary drinks overall and across beverage type is required to comprehensively assess population intake. Monitoring sugary drink consumption across socioeconomic position (SEP) is critical to understanding where inequities exist and their contribution to non-communicable disease risk. Low SEP groups have been found to consume more SSB and $100 \%$ juice in the USA (SEP: income and education) (Drewnowski \& Rehm, 2015; Han \& Powell, 2013), the United Kingdom (SEP: income) (Briggs et al., 2013) and Australia (SEP: income; SSB only) (Lal et al., 2017). In Canada, no differences in per capita SSB or $100 \%$ juice intake were observed across income (Jones et al., 2019), whereas intake across education and food security has yet to be established.

Comprehensive assessments of sugary drink consumption in Canada are needed. First, SEP indicators are not interchangeable proxies and descriptions of inequities associated with health knowledge (education), material resources (education, income and food security status) and material deprivation beyond accessing nutritious food (food security) are warranted (Braveman et al., 2005; Kirkpatrick et al., 2015). Moreover, ageand sex-specific patterns of sugary drink consumption across SEP should be considered. For example, compared to females, 
males have a higher prevalence of sugary drink consumption and consume more energy from these beverages in Canada (Garriguet, 2019; Jones et al., 2019; Langlois et al., 2019) and other high income countries (GBD, 2018). Finally, accounting for the episodic nature of beverage consumption is needed to better estimate social inequities in sugary drink consumption (Garriguet, 2019). Specifically, it is important to estimate the potential socioeconomic inequities in the prevalence of consumers, given that any consumption of these beverages is not recommended. Moreover, estimating socioeconomic inequities in mean energy intake from beverages allows us to assess the contribution of overall energy consumption among those who consumed (WHO, 2015).

Our objective was to estimate the sex-specific consumption of sugary drinks, SSB and $100 \%$ juice across SEP in a population-representative sample of Canadian children/ adolescents and adults. This study fills a critical knowledge gap regarding the extent to which social inequities in sugary drink consumption exist in Canada.

\section{Methods}

\section{Study population}

We conducted a cross-sectional analysis of the nationally representative 2015 Canadian Community Health Survey-Nutrition (CCHS-N) Public Use Microdata File (Health Canada, 2017). The CCHS-N was conducted by Statistics Canada to assess dietary intakes of Canadians for the first time since 2004 using interviewer-administered 24-h dietary recalls using an adapted version of the Automated Multi-Pass Method from the United States Department of Agriculture (Statistics Canada, 2018). This survey used a multi-stage, cluster sampling approach to secure a sample of 20,487 Canadians aged 1 year and older living in private dwellings across the 10 provinces (61\% response rate) (Health Canada, 2017).

We included single-day $24-\mathrm{h}$ dietary recalls among Canadians 2 years and older $(n=20,115)$. We excluded respondents if they were breastfeeding or reported no energy intake $(n=200)$, or were missing information on income $(n=22)$, education $(n=41)$ or food security $(n=110)$. Our final analytic sample was 19,742 respondents. This study was approved by the Ethics Review Board at Public Health Ontario.

\section{Beverage types: sugary drinks, sugar-sweetened beverages (SSB) and $100 \%$ juice}

We assessed sugary drink, SSB and $100 \%$ juice consumption separately. We applied Health Canada's definition of sugary drinks (Health Canada, 2019a) to derive beverage types using Nutrition Survey System (NSS) codes linked to Canadian Nutrient File descriptions (see Appendix 1, Table 3$)$. Sugary drink codes $(N=249)$ represent the sum of SSB $(N=190)$ and $100 \%$ juice $(N=59)$ codes. Our beverage categorization aligned with a previous Canadian study (Jones et al., 2019), with additional exclusion of beverages with sugar added by consumer (e.g., tea and coffee) and inclusion of sugary drinks consumed with alcohol. Diet/ low-calorie beverages, infant formulas, functional beverages (e.g., meal replacements) and alcoholic beverages (e.g., pure alcohol, beer, wine, pre-mixed seltzers) were not included as sugary drinks.

Beverage consumption categories are not mutually exclusive because sugary drink consumers include consumers of either SSB or $100 \%$ juice or both SSB and $100 \%$ juice. We estimated sugary drink, SSB and $100 \%$ juice intake using two measures: (1) prevalence of consumers on a given day, defined as the proportion that reported consuming each beverage type on the day prior to the 24-h recall interview; and (2) mean energy intake (kilocalories (kcal)) among those who consumed each beverage type on a given day, estimated among those who consumed the day prior to the 24-h recall interview. To further quantify energy intake, we estimated the relative contribution of energy from each beverage type. We report averages; therefore, a single dietary recall was sufficient considering mean intake on a given day reflects mean usual intake (Garriguet, 2019).

\section{Socioeconomic position}

The highest level of household education was categorized using four groups: 'Less than high school', 'High school diploma', 'Certificate below bachelor's degree' (e.g., a trade, college or non-bachelor certificate) and 'Bachelor degree or above'. Household food security status was assessed using eight questions for children/adolescents (aged 2-18) and ten for adults (aged 19 and over) with responses classified as either food secure (i.e., answered 'yes' to $0-1$ questions about difficulty with income-related food access) or food insecure (moderate or severe, i.e., answered 'yes' to two or more questions about compromised quality/quantity or reduced food intake due to disrupted eating patterns) (Statistics Canada, 2018). Household income adequacy quintiles were derived based on the adjusted ratio of the respondents' total household income reported in the previous 12 months to the low income cutoff corresponding to their household and community size (Statistics Canada, 2018).

\section{Covariates}

We stratified our sample by sex (female or male) and age (children/adolescents, 2-18 years or adults, 19 years and older). 


\section{Statistical analysis}

We ran separate models for each outcome and SEP indicator. We applied modified Poisson regressions to estimate prevalence, prevalence differences and ratios (Appendix 1, Tables 6 and 7), and corresponding 95\% confidence intervals $(95 \% \mathrm{CI})$ across SEP using post-estimation marginal means analysis (Zou, 2004). Among those who consumed on a given day, we conducted linear regressions to estimate mean energy intake from each beverage type across SEP. For each beverage type, we estimated the relative (\%) contribution of mean energy intake to the total energy intake from all sources. Primary analyses were unadjusted to describe consumption in a nationally representative sample (Conroy $\&$ Murray, 2020).

We conducted two sensitivity analyses. The residuals for the energy outcomes were right-skewed; therefore, we conducted square root-transformed regression and then backtransformed to original scale post-regression. Comparisons with the primary analysis revealed no differences in energy intake patterns (not shown); therefore, we reported untransformed energy outcomes to reflect reported energy intake from the CCHS-N (Lumley et al., 2002). Furthermore, we adjusted all models for dietary energy misreporting (under, over, plausible reporters, unclassified) to account for systematic error in self-reported dietary assessments (Appendix 2) (Garriguet, 2018).

We applied survey weights and bootstrap replicates $(N=500)$ provided by Statistics Canada in all models and used survey procedures ensuring results were representative of the Canadian population and appropriate variance estimation, respectively. Analyses were completed using SAS (v.9.4) and STATA (v.15).

\section{Results}

\section{Prevalence of sugary drink, SSB and $100 \%$ juice consumers on a given day}

Sex-specific prevalence of sugary drink, SSB and 100\% juice consumers on a given day by SEP for children/ adolescents is presented in Fig. 1 (estimates in Appendix 1, Table 4). Among female and male children/adolescents, the prevalence of consuming sugary drinks (females: $72 \%$ (95\% CI: 68, 75); males: 78\% (95\% CI: 75, 80)), SSB (females: 52\% (95\% CI: 49, 56); males: 56\% (95\% CI: 53, 59)) and 100\% juice (females: $37 \%$ (95\% CI: 33, 40); males: $42 \%$

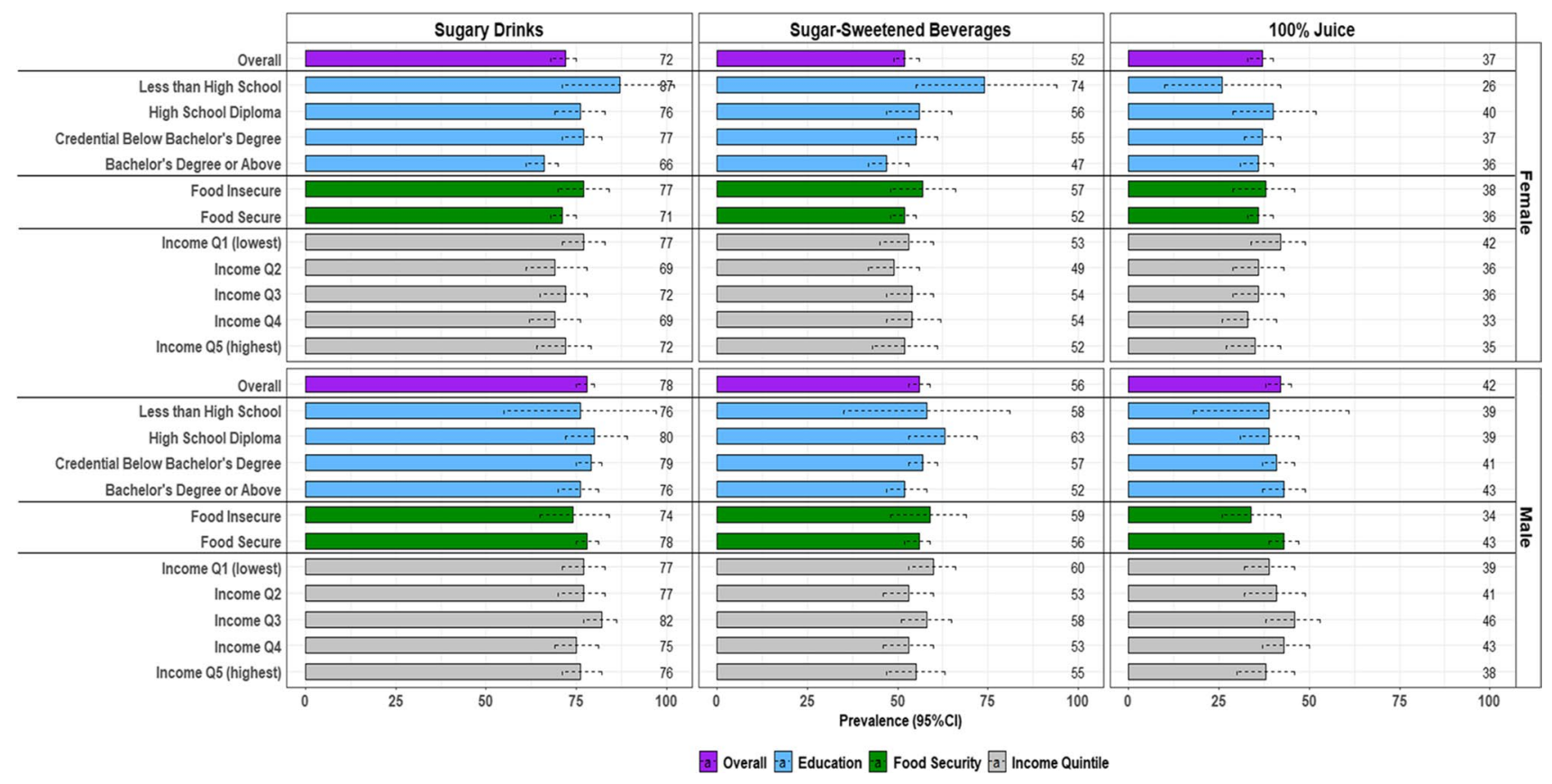

Fig. 1 Sex-specific prevalence (\%) of sugary drink consumption, on a given day, by beverage type and socioeconomic position in children/adolescents. Data source: 2015 Canadian Community Health Survey-Nutrition. Children/adolescents include respondents aged 2-18 years (females: 3050; males: 3064). SEP indicators include highest household educational attainment, household food security status and household income quintiles. Dotted lines represent $95 \%$ confidence intervals (CI). Prevalence values for the point estimates are included along the right-hand side of each figure. Figure created in R-Studio 
(95\% CI: 38, 45)) on a given day was high. The absolute prevalence difference of sugary drink consumers ranged from 11 to 21 percentage-points higher among females in households with lower education ('Less than high school', 'High school diploma' and 'Certificate below bachelor's degree') compared to 'Bachelor's degree or above'. Similarly, the prevalence of SSB consumers ranged from 8 to 27 percentage-points higher among females in households with lower education compared to those with 'Bachelor's degree or higher'. Among males, the prevalence of $100 \%$ juice consumers was $9(95 \% \mathrm{CI}:-18,0)$ percentage-points lower in food insecure compared to food secure households. In females, a lack of precision (i.e., uncertainty) was observed for the estimates related to higher prevalence of sugary drink and, separately, SSB consumers in food insecure compared to food secure and low compared to high income households (for sugary drinks only). In males, uncertainty surrounded higher prevalence of SSB consumers across education and comparing lowest to highest income. There was no clear pattern between the prevalence of $100 \%$ juice consumers and SEP in females and across education and income for males.
Sex-specific prevalence of sugary drink, SSB and $100 \%$ juice consumers on a given day by SEP in adults is presented in Fig. 2 (estimates in Appendix 1, Table 5). Among female adults, the prevalence of consuming on a given day was $50 \%(95 \% \mathrm{CI}: 47,52)$ for sugary drinks, $35 \%$ (95\% CI: 33, 38) for SSB and 22\% (95\% CI: 20, 24) for $100 \%$ juice. On the absolute scale, the prevalence of sugary drink and, separately, SSB female adult consumers in food insecure households was 10 (95\% CI: 1, 19) and 14 (95\% CI: 2, 27) percentage-points higher than food secure households, respectively. Moreover, among female adults, consumption of sugary drinks among the lowest (Q1) and fourth income quintile (Q4), respectively, was 11 (95\% CI: 1, 20) and 10 (95\% CI: 2, 19) percentagepoints higher compared to the highest (Q5) quintile. Uncertainty surrounded the higher prevalence estimates of increased sugary drink consumption comparing Q2 and Q3 income groups to Q5 and the higher estimates of SSB consumption among lower income groups. There was no clear pattern across education for SSB consumption and across all SEP indicators for $100 \%$ juice consumption in females.

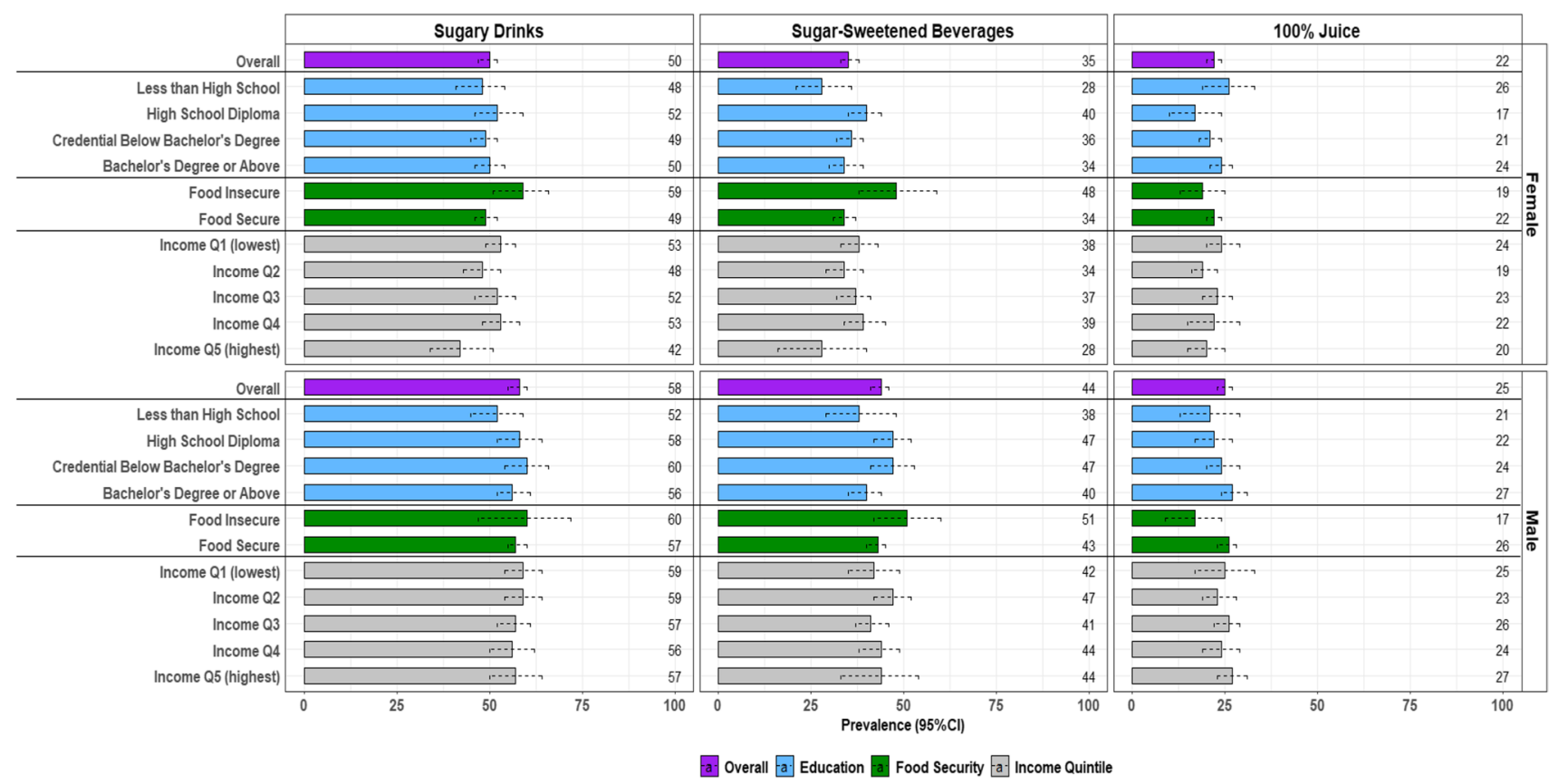

Fig. 2 Sex-specific prevalence (\%) of sugary drink consumption, on a given day, by beverage type and socioeconomic position in adults. Data source: 2015 Canadian Community Health Survey-Nutrition. Adults include respondents aged 19 years and older (females: 7219; males: 6409). SEP indicators include highest household educational attainment, household food security status and household income quintiles. Dotted lines represent 95\% confidence intervals (CI). Prevalence values for the point estimates are included along the right hand side of each figure. Figure created in R-Studio 
Among male adults, the prevalence of consuming on a given day was $58 \%(95 \% \mathrm{CI}: 55,60)$ for sugary drinks, $44 \%$ (95\% CI: 41, 46) for SSB and 25\% (95\% CI: $23,27)$ for $100 \%$ juice. No differences were observed in the prevalence of sugary drink consumers across SEP. The prevalence of SSB consumers was between 7 and 8 percentage-points higher among males with 'High school diploma' and 'Credential below bachelor's degree' compared to 'Bachelor's degree or above' and 9 (95\% CI: - 1, 19) percentage-points higher among males from food insecure compared to food secure households. Conversely, the prevalence of $100 \%$ juice consumers was $9(95 \% \mathrm{CI}:-18,0)$ percentage-points lower among male adults from food insecure compared to food secure households. There is additional evidence that low education males are consuming less $100 \%$ juice than their high SEP counterparts. Given the uncertainty around the estimates, additional confirmation is required to support interpretations.

Sex-specific prevalence ratios of sugary drink, SSB and $100 \%$ juice consumers on a given day by SEP for children/ adolescents (Appendix 1, Table 6) and adults (Appendix 1, Table 7) followed the same patterns described for the absolute differences.

\section{Mean energy intake from sugary drinks, SSB and $100 \%$ juice, among consumers on a given day}

Sex-specific mean energy intake from beverages among children/adolescents who consumed sugary drinks, SSB and $100 \%$ juice on a given day by SEP is presented in Table 1. Among female children/adolescents, mean daily energy intake was $211 \mathrm{kcal}$ (95\% CI: 200, 223) from sugary drinks, $197 \mathrm{kcal}(184,210)$ from SSB and $132 \mathrm{kcal}(95 \% \mathrm{CI}: 122,143)$ from $100 \%$ juice, representing $12 \%, 11 \%$ and $8 \%$ of overall energy intake among consumers on a given day, respectively. No social inequities in mean energy intake were observed.

Among male children/adolescents, mean energy intake was $252 \mathrm{kcal}(95 \% \mathrm{CI}: 234,270)$ from sugary drinks, $238 \mathrm{kcal}(95 \% \mathrm{CI}: 215,260)$ from SSB and $149 \mathrm{kcal}$ (95\% CI: 136, 163) from $100 \%$ juice, representing $12 \%$, $11 \%$ and $7 \%$ of overall energy intake among consumers, respectively. While the relative contribution of overall energy intake from sugary drinks and SSB was 3\% higher among male children/adolescents with 'Less than high school' compared to 'Bachelor's degree or above', uncertainty surrounded the mean differences. There were no clear patterns observed across SEP for $100 \%$ juice consumers.
Sex-specific mean energy intake among adult consumers of sugary drinks, SSB and $100 \%$ juice on a given day by SEP is presented in Table 2. Among female adults, mean energy intake was $186 \mathrm{kcal}(95 \% \mathrm{CI}: 175,198)$ from sugary drinks, $193 \mathrm{kcal}(95 \%$ CI: 180, 206) from SSB and $113 \mathrm{kcal}(95 \%$ CI: 102,124$)$ from $100 \%$ juice, representing $11 \%, 11 \%$ and $6 \%$ of overall energy intake among consumers, respectively. Food insecure consumers, on average, consumed $27 \mathrm{kcal}$ (95\% CI: 3, 51) more energy from sugary drinks. Similar inequities were observed for SSB consumption across food security; however, additional verification is required due to uncertainty related to small sample size. One-hundred percent juice consumers with 'Less than high school' consumed, on average, $35 \mathrm{kcal}$ (95\% CI: 2, 67) more energy from $100 \%$ juice than female consumers with 'Bachelor's degree or above'.

Among male adults, mean energy intake from beverages was $243 \mathrm{kcal}(95 \% \mathrm{CI}: 230,257)$ from sugary drinks, $246 \mathrm{kcal}(95 \% \mathrm{CI}: 230,261)$ from SSB and $134 \mathrm{kcal}$ (95\% CI: 123,145 ) from $100 \%$ juice, representing $10 \%$, $10 \%$ and $6 \%$ of overall daily energy intake, respectively. Sugary drink consumers with 'High school diploma' and 'Credential below bachelor's degree' consumed, on average, 68 and $39 \mathrm{kcal}$ more energy from sugary drinks compared to those with 'Bachelor's degree or above'. Similar patterns were observed for SSB energy intake across education. While the relative contribution of energy intake among sugary drink and, separately, SSB consumers was $4 \%$ higher among food insecure compared to food secure male adults, the uncertainty surrounding the mean differences requires further verification. No patterns in energy intake were observed among male adult 100\% juice consumers across SEP.

\section{Accounting for systematic error related to energy misreporting}

Adjusted intake patterns for dietary misreporting were consistent with the primary analyses (available upon request).

\section{Discussion}

This study identified sex-specific social inequities in sugary drink and SSB consumption in a nationally representative sample of Canadians, but patterns were inconsistent for $100 \%$ juice. Low education was associated with higher prevalence of sugary drink and SSB consumption on a given day among female children/adolescents, while food insecurity and low income were associated with a higher 


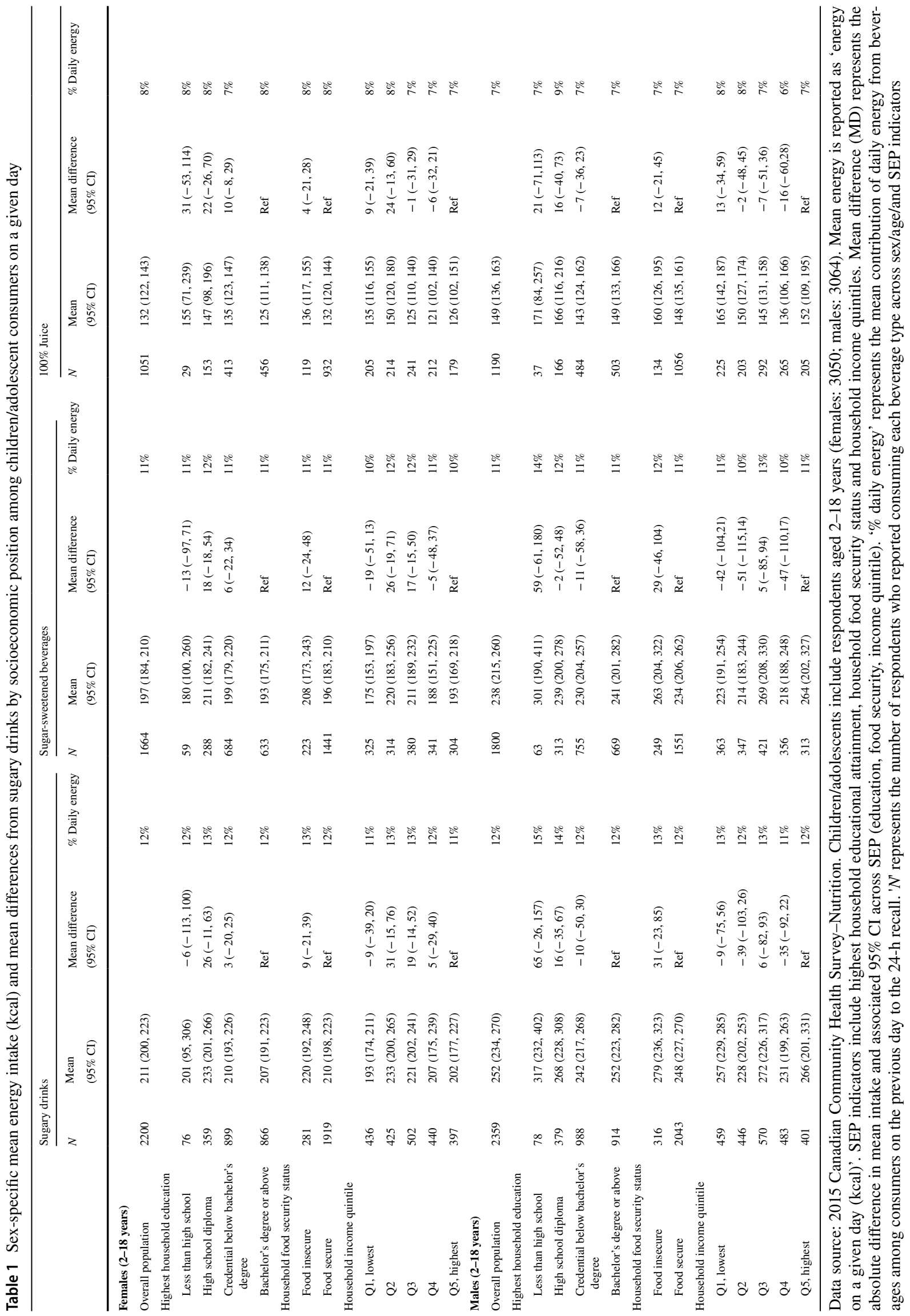




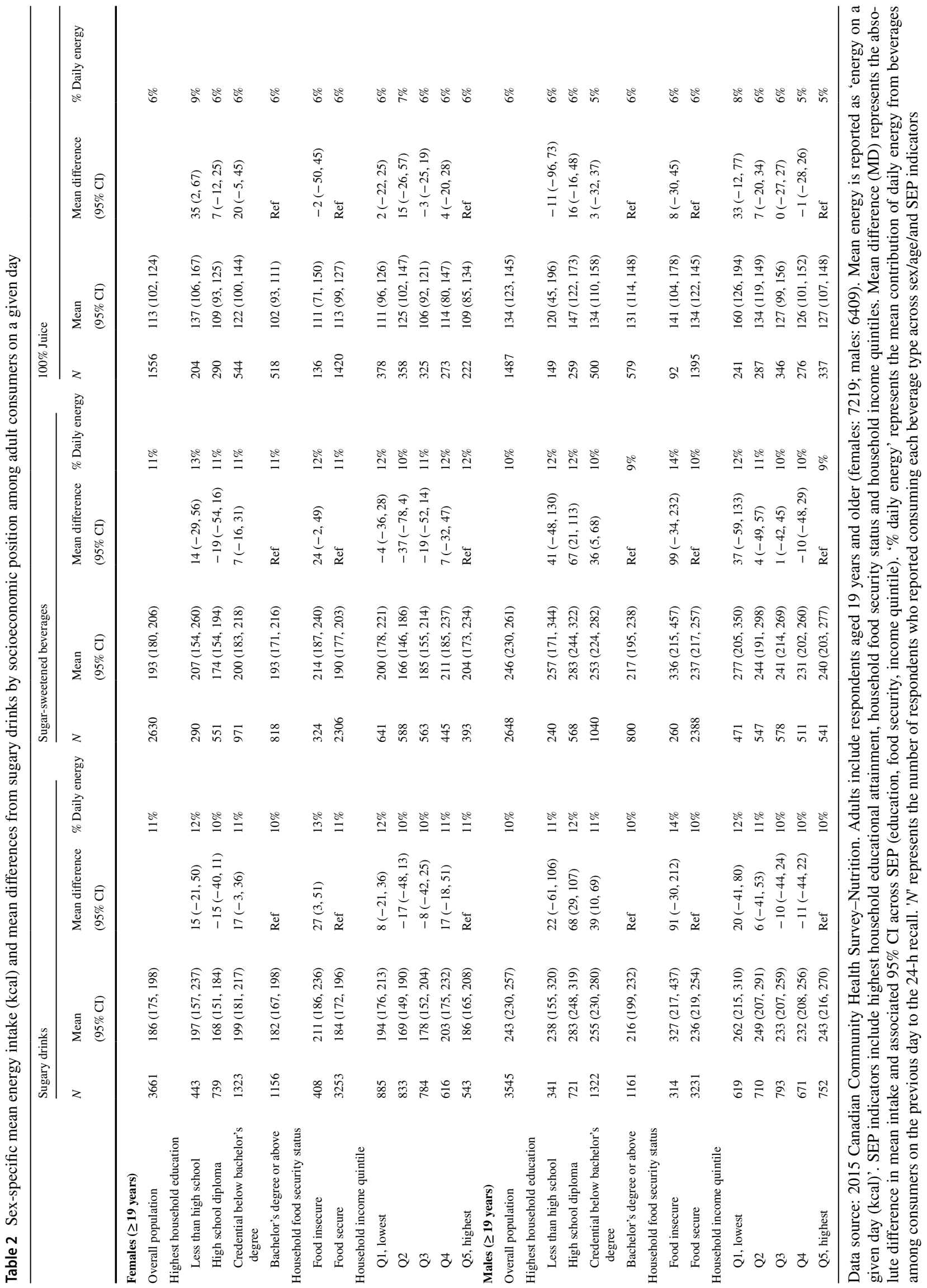


prevalence of sugary drink consumption in female adults. Among male children/adolescents and adults, a lower prevalence of $100 \%$ juice consumption on a given day was observed among food insecure compared to food secure groups. Among consumers on a given day, higher mean energy intake from sugary drinks and SSB was observed across food security in female adults and education in male adults. Among female adults who consumed $100 \%$ juice, low education was associated with higher energy intake. Across all SEP groups, Canadians reported a high prevalence of sugary drink, SSB and $100 \%$ juice consumption on a given day and have mean energy intake levels associated with poor health outcomes (WHO, 2015). Together our findings indicate the need for pro-equity interventions to reduce consumption among Canadians.

Population-level interventions such as informational and financial policies have potential to reduce unhealthy beverage consumption and may influence manufacturers to produce healthier products (Krieger et al., 2021). Informational interventions, including Canada's 'replace sugary drinks with water' messaging (Health Canada, 2019b) or trafficlight labelling interventions (von Philipsborn et al., 2019), are important, but likely insufficient for achieving this goal. Moreover, informational interventions may impose literacy burdens on consumers, limiting access for certain groups (Krieger et al., 2021). Taxation policies are considered pro-equity interventions given the beneficial impact across subpopulations. Internationally, SSB taxation policies are associated with reduced SSB sales concentrated among lower SEP groups (Krieger et al., 2021; Popkin \& Ng, 2021). Modelling studies have demonstrated the potential for beverage taxation policies to reduce social inequities in non-communicable diseases and increase healthcare cost savings concentrated among lower SEP groups (Kao et al., 2020; Lal et al., 2017). Finally, limiting SSB availability in subsidized food programs may improve diet quality of recipients, particularly when paired with incentives to increase fruit/vegetable purchases (Krieger et al., 2021).

Establishing baseline levels of beverage consumption by age, sex and SEP is essential for guiding the choice and design of interventions to equitably reduce sugary drink consumption and associated non-communicable disease in Canada (Popkin \& Ng, 2021). Few studies have examined the association between SEP and sugary drink consumption, an important risk factor for health outcomes (Briggs et al., 2013; Han \& Powell, 2013; Jones et al., 2019; Lal et al., 2017). A previous Canadian study using the CCHS-N reported no differences in per capita energy intake from SSB across income levels (Jones et al., 2019). Our study expanded upon this analysis by assessing total sugary drinks, incorporating the episodic nature of beverage consumption, disaggregating findings by sex, describing outcomes across income quintiles and examining additional household SEP measures (educational attainment and food security status). In our study, more patterns emerged for food security status and educational attainment compared to income for sugary drinks and SSB consumption, highlighting the importance of describing patterns across multiple SEP indicators in heath research (Braveman et al., 2005). To our knowledge, this is the first Canadian study to include food security status as an independent exposure of sugary drink intake incorporating work that identified food security status as a strong predictor of differential nutrient intake in Canada (Kirkpatrick et al., 2015). Our findings related to SSB consumption across education are consistent with associations found in the USA (Han \& Powell, 2013). More income-related inequities in SSB consumption were observed in the USA, the UK and Australia compared to our study (Briggs et al., 2013; Han \& Powell, 2013; Lal et al., 2017), which may be related to different subgroups and income measures analyzed across studies.

Our study found no clear pattern between SEP and 100\% juice consumption consistent with a previous Canadian assessment of $100 \%$ juice energy intake across income quartiles (Jones et al., 2019). In our study, energy intake among female adult consumers from $100 \%$ juice was higher in the lowest education group. Conversely, males had a lower prevalence of $100 \%$ juice consumption in food insecure compared to secure groups. Despite the variability in our findings across $100 \%$ juice, monitoring social inequities in $100 \%$ juice consumption is important, as these have been observed in the USA (Drewnowski \& Rehm, 2015) and the UK (Briggs et al., 2013). Differential uptake of Canada's Food Guide recommendations to replace sugary drinks with water across SEP (Health Canada, 2019b), coupled with the lower cost of $100 \%$ juice compared to whole fruits and vegetables, could generate unintended inequities in $100 \%$ juice consumption (Darmon \& Drewnowski, 2015).

This study has limitations. Our study relies on data collected in 2015 and may not reflect temporal changes to dietary intake patterns; however, we leveraged the most recent population-level nutrition data available. Social desirability bias in self-reported responses may have led to underestimates of consumption in some groups (e.g., females and higher SEP), which would bias observed social inequities towards the null (Garriguet, 2018). For example, self-reported beverage intakes in the CCHS-N were consistently lower than Canadian beverage sales 
over the same time period (Czoli et al., 2019). Therefore, we adjusted all models for energy misreporting status in our sensitivity analyses, which had minimal impact on our findings. Low sample sizes across SEP groups likely resulted in insufficient power to detect significant associations, particularly in children/adolescents; however, sole reliance on statistical significance for interpretations in epidemiology is incomplete (Wasserstein \& Lazar, 2016). Analyses of single-day dietary recall estimates are prone to random error associated with within-person variability, which can be accounted for through analyses of multiple dietary recalls, such as the National Cancer Institute's method for estimating usual dietary intake (Tooze et al., 2006). This bias may have contributed to the reduced precision of mean energy intake estimates across SEP due to smaller sample sizes in these analyses; however, for means a single 24 -h recall is sufficient and our approach allowed us to assess our specific a priori research questions related to socioeconomic differences in the prevalence, per-consumer energy intake and relative contribution of total energy, on a given day. Twentyfour-hour recalls are prone to systematic error in energy reporting, which have been accounted for in the study design and sensitivity analysis (Health Canada, 2017). Reliance on the CNF descriptions to categorize beverages may have led to misclassification of certain codes; however, our categorizations are generally consistent with a previous study using the CCHS-N (Jones et al., 2019). Finally, inclusion of only pre-sweetened beverages likely underestimated consumption, though population-level interventions generally target pre-made items (Popkin \& $\mathrm{Ng}$, 2021; von Philipsborn et al., 2019).

This study's strengths include analyzing three distinct primary exposures of household SEP to describe SEPspecific consumption patterns (Braveman et al., 2005; Kirkpatrick et al., 2015). We observed differential consumption patterns by sex, highlighting the importance of assessing sex-specific associations in health research (Johnson et al., 2009). We applied methods to analyze episodically consumed beverages (Han \& Powell, 2013) and analyzed separate consumption patterns for sugary drinks,
SSB and $100 \%$ juice associated with free, added and natural sugars, respectively (WHO, 2015). Finally, we included a comprehensive assessment of traditional and novel beverage types (Czoli et al., 2019; Jones et al., 2019).

\section{Conclusion}

To our knowledge, this is the first study to describe age- and sex-specific sugary drink, SSB and $100 \%$ juice consumption patterns across multiple indicators of SEP in a representative sample of Canadians. Future research on the effectiveness of interventions to equitably reduce sugary drink consumption in the Canadian context is warranted.

\section{Contributions to knowledge}

What does this study add to existing knowledge?

- This study adds to a growing body of evidence highlighting population and socioeconomic patterns of beverage consumption by including multiple socioeconomic indicators (education, food security status and income adequacy quintile) to describe differential patterns of beverage intake. In addition, population-level intake on a given day was high across all SEP groups by age and sex.

What are the key implications for public health interventions, practice or policy?

- The design and implementation of pro-equity populationlevel interventions that reduce sugary drink consumption in the Canadian population are warranted.

- Informational, financial, healthy defaults and limited availability interventions should be considered in reference to baseline consumption patterns for the design and implementation of sustainable strategies targeting food and social environments in Canada. 


\section{Appendix 1}

Table 3 Nutrient Survey System codes and Canadian Nutrient File descriptions for beverage groupings categorized as sugary drinks, sugarsweetened beverages and $100 \%$ juice

\begin{tabular}{|c|c|}
\hline Nutrient Survey System code & Canadian Nutrient File description \\
\hline \multicolumn{2}{|c|}{$100 \%$ Juice (beverage types: sugary drink, $100 \%$ juice) } \\
\hline 1485 & Acerola juice, raw \\
\hline 1495 & Apple juice, canned or bottled, without added vitamin C \\
\hline 1497 & Apple juice, frozen concentrate, diluted, without added vitamin $\mathrm{C}$ \\
\hline 1572 & Grapefruit juice, white, raw \\
\hline 1576 & Grape juice, canned or bottled, without added vitamin C \\
\hline 1589 & Lemon juice, raw \\
\hline 1590 & Lemon juice, canned or bottled \\
\hline 1591 & Lemon juice, frozen \\
\hline 1594 & Lime juice, raw \\
\hline 1595 & Lime juice, canned or bottled \\
\hline 1619 & Orange juice, raw \\
\hline 1620 & Orange juice, chilled, includes from concentrate \\
\hline 1622 & Orange grapefruit juice, canned \\
\hline 1624 & Tangerine (mandarin) juice, raw \\
\hline 1631 & Passion fruit juice, purple, raw \\
\hline 1632 & Passion fruit juice, yellow, raw \\
\hline 1657 & Pineapple juice, canned, added vitamin C \\
\hline 1659 & Pineapple juice, frozen concentrate, diluted \\
\hline 1673 & Prune juice, canned \\
\hline 1716 & Grapefruit juice, canned, no added sugar \\
\hline 1723 & Orange juice, canned \\
\hline 1725 & Orange juice, frozen concentrate, diluted \\
\hline 1752 & Apple juice, canned or bottled, added vitamin $\mathrm{C}$ \\
\hline 1754 & Apple juice, frozen concentrate, diluted, added vitamin $\mathrm{C}$ \\
\hline 2312 & Carrot juice, canned \\
\hline 2464 & Juice, tomato, canned \\
\hline 2473 & Vegetable juice cocktail, canned \\
\hline 2868 & Juice, tomato clam cocktail, canned \\
\hline 5287 & Juice drink, mixed vegetable and fruit \\
\hline 5389 & Blackberry juice, canned \\
\hline 5472 & Orange-strawberry-banana juice \\
\hline 5586 & Juice, tomato and vegetable, low sodium \\
\hline 5593 & Cranberry juice, unsweetened \\
\hline 6203 & Orange juice, chilled, includes from concentrate, fortified with added calcium and vitamin D \\
\hline 6287 & Juice, tomato, canned, no salt added \\
\hline 6440 & Grapefruit juice, pink, raw \\
\hline 6660 & Grape juice, canned or bottled, unsweetened, with added vitamin C \\
\hline 6661 & Pomegranate juice, ready-to-drink \\
\hline 7051 & Orange pineapple juice \\
\hline 7224 & Beverage, coconut water, unsweetened, ready-to-drink \\
\hline 7419 & Apple juice, canned or bottled, unsweetened, calcium and vitamins $\mathrm{C}$ and $\mathrm{D}$ added \\
\hline 7421 & Vegetable juice cocktail, canned, low sodium \\
\hline 7573 & Orange juice, frozen concentrate, diluted, with added calcium and vitamin D \\
\hline 404283 & Fruit juice blend, $100 \%$ juice, with vitamins and minerals \\
\hline 501855 & Orange and banana juice \\
\hline 501857 & Pineapple-grapefruit juice, fresh \\
\hline 501862 & Pineapple-orange juice, NFS, includes from concentrate \\
\hline 501866 & Pineapple-orange juice, frozen, diluted with water \\
\hline 501927 & Fruit juice, NFS (mixed fruit juices) \\
\hline 502123 & Mixed vegetable juice (vegetables other than tomato) \\
\hline
\end{tabular}


Table 3 (continued)

\begin{tabular}{|c|c|}
\hline Nutrient Survey System code & Canadian Nutrient File description \\
\hline 504002 & Apple cider \\
\hline 504189 & Pineapple juice-non-citrus juice blend, unsweetened, with added vitamin $\mathrm{C}$ \\
\hline 504190 & Pineapple, orange and banana juice \\
\hline 504388 & Fruit juice blend, $100 \%$ juice, with added vitamin C \\
\hline 504477 & Orange juice, frozen concentrate, unsweetened, diluted \\
\hline 504478 & Orange juice, frozen concentrate, with calcium and vit. D added, diluted \\
\hline 504731 & Orange juice, frozen concentrate, diluted with 4 parts water \\
\hline 504732 & Orange juice, frozen concentrate, diluted with 3.5 parts water \\
\hline 505135 & Orange juice, NFS \\
\hline \multicolumn{2}{|c|}{ Sugar-Sweetened Fruit Drink (beverage type: sugary drink, sugar-sweetened beverage) } \\
\hline 1570 & Grapefruit juice, canned, sweetened \\
\hline 1625 & Tangerine (mandarin) juice, canned, sugar added \\
\hline 1629 & Papaya nectar, canned \\
\hline 1644 & Peach nectar, canned \\
\hline 1652 & Pear nectar, canned \\
\hline 1694 & Apricot nectar, canned \\
\hline 1717 & Grapefruit juice, frozen concentrate, diluted \\
\hline 1720 & Grape juice, frozen concentrate, sugar and vitamin $\mathrm{C}$ added, diluted \\
\hline 2885 & Juice drink, cranberry and apricot, bottled \\
\hline 2889 & Juice drink, citrus fruit, frozen concentrate, water added \\
\hline 2893 & Lemonade, white, frozen concentrate, water added \\
\hline 2895 & Limeade, frozen concentrate, water added \\
\hline 2904 & Juice drink, orange and apricot, canned \\
\hline 2922 & Juice drink, fruit punch, frozen concentrate, water added \\
\hline 2940 & Lemonade, pink, frozen concentrate, water added \\
\hline 2954 & Juice drink, cranberry-apple, vitamin $\mathrm{C}$ added, bottled \\
\hline 2955 & Juice drink, cranberry-grape, vitamin $\mathrm{C}$ added, bottled \\
\hline 2956 & Juice, cocktail, cranberry, vitamin $\mathrm{C}$ added, bottled \\
\hline 2958 & Drink, fruit punch flavour, vitamin $\mathrm{C}$ added, powder, water added \\
\hline 2959 & Drink, fruit punch, vitamin $\mathrm{C}$ added, ready-to-drink \\
\hline 2960 & Juice drink, grape, vitamin $\mathrm{C}$ added, canned \\
\hline 2961 & Drink, grape, vitamin $\mathrm{C}$ added, canned \\
\hline 2965 & Drink, lemonade flavour, vitamin $\mathrm{C}$ added, powder, water added \\
\hline 2967 & Drink, orange, vitamin $\mathrm{C}$ added, canned \\
\hline 2968 & Juice drink, pineapple and grapefruit, vitamin $\mathrm{C}$ added, canned \\
\hline 2969 & Juice drink, pineapple and orange, vitamin $\mathrm{C}$ added, canned \\
\hline 2972 & Drink, orange flavour, vitamin $\mathrm{C}$ added, powder, water added \\
\hline 2974 & Drink, orange, vitamin $\mathrm{C}$ added, frozen concentrate, water added \\
\hline 2976 & Juice, cocktail, cranberry, vitamin $\mathrm{C}$ added, frozen concentrate, water added \\
\hline 2981 & Drink, fruit punch flavour, powder, water added \\
\hline 2983 & Drink, lemonade flavour, powder, water added \\
\hline 5424 & Drink, breakfast type, orange, ready-to-drink \\
\hline 5628 & Cocktail mix, non-alcoholic, concentrated, frozen \\
\hline 6204 & Guava, nectar, canned \\
\hline 6205 & Mango, nectar, canned \\
\hline 6437 & Drink, fruit punch, frozen concentrate, water added \\
\hline 6470 & Juice drink, orange \\
\hline 6662 & Juice, apple and grape, with added vitamin $\mathrm{C}$ \\
\hline 7055 & Drink, fruit flavour, vitamin $\mathrm{C}$ added, ready-to-drink \\
\hline 7070 & Juice drink, fruit, ready-to-drink \\
\hline 7230 & Juice drink, orange, calorie-reduced \\
\hline 404292 & Juice drink, fruit, without added vitamin C, ready-to-drink \\
\hline 501853 & Grapefruit and orange juice, fresh, with sugar \\
\hline 501935 & Prune juice, with sugar \\
\hline 501936 & Banana nectar \\
\hline
\end{tabular}


Table 3 (continued)

\begin{tabular}{|c|c|}
\hline Nutrient Survey System code & Canadian Nutrient File description \\
\hline 501937 & Cantaloupe nectar \\
\hline 501940 & Passion fruit nectar \\
\hline 501941 & Soursop (Guanabana) nectar \\
\hline 502464 & Fruit punch, made with fruit juice and soda \\
\hline 502465 & Fruit punch, made with soda, fruit juice, and sherbet or ice cream \\
\hline 502468 & Lemonade, frozen, diluted with water \\
\hline 502469 & Lemon-limeade \\
\hline 502470 & Limeade, frozen concentrate, diluted \\
\hline 502472 & Citrus fruit juice drink, frozen concentrate, diluted ( $40-50 \%$ fruit juice) \\
\hline 502479 & Fruit-flavoured drink, made from powdered mix (lemonade) \\
\hline 502480 & Lemonade, drink, powder, with sugar and vitamin $\mathrm{C}$ added, water added \\
\hline 504387 & Daiquiri mix, frozen concentrate, diluted \\
\hline 504510 & Pina Colada, non-alcoholic \\
\hline 504558 & Shirley Temple \\
\hline 504686 & Carbonated citrus juice drink \\
\hline 504733 & Juice drink, fruit punch, frozen concentrate, diluted with 3.5 parts water \\
\hline 504734 & Juice drink, fruit punch, frozen concentrate, diluted with 4 parts water \\
\hline 504735 & Juice drink, fruit punch, frozen concentrate, diluted with 5 parts water \\
\hline 505134 & Grapefruit juice, frozen (reconstituted with water) \\
\hline 505188 & Carbonated juice drink, NS as to type of juice \\
\hline 505189 & Carbonated noncitrus juice drink \\
\hline \multicolumn{2}{|c|}{ Regular soft drink (beverage type: sugary drink, sugar-sweetened beverage) } \\
\hline 2854 & Carbonated drinks, cream soda \\
\hline 2855 & Carbonated drinks, ginger ale \\
\hline 2856 & Carbonated drinks, grape soda \\
\hline 2857 & Carbonated drinks, lemon-lime soda \\
\hline 2858 & Carbonated drinks, orange soda \\
\hline 2859 & Carbonated drinks, pepper type \\
\hline 2860 & Carbonated drinks, tonic water (quinine) \\
\hline 2861 & Carbonated drinks, root beer \\
\hline 2920 & Carbonated drinks, cola, fast food cola \\
\hline 4980 & Carbonated drinks, cola, decaffeinated \\
\hline 5288 & Carbonated drinks, cola \\
\hline 5293 & Carbonated drinks, chocolate \\
\hline 7429 & Carbonated drinks, lemon-lime soda, with caffeine \\
\hline \multicolumn{2}{|c|}{ Sugar-sweetened milk (beverage type: sugary drink, sugar-sweetened beverage) } \\
\hline 55 & Eggnog, $7 \%$ M.F., Canadian product, $4 \%$ to $8 \%$ M.F. \\
\hline 69 & Milk, fluid, chocolate, whole \\
\hline 70 & Milk, fluid, chocolate, partly skimmed, $2 \%$ M.F. \\
\hline 75 & Milk shake, chocolate, thick \\
\hline 76 & Milk shake, vanilla, thick \\
\hline 2863 & Beverage mix, carob flavour, powder, with whole milk \\
\hline 2865 & Beverage mix, chocolate flavour, powder, with whole milk \\
\hline 2896 & Malted milk, natural flavour, enriched powder \\
\hline 2899 & Malted milk, natural flavour, powder, with whole milk \\
\hline 2900 & Malted milk, chocolate flavour, enriched powder \\
\hline 2903 & Malted milk, chocolate flavour, powder, with whole milk \\
\hline 2905 & Milk shake (fast food), chocolate \\
\hline 2906 & Milk shake (fast food), vanilla \\
\hline 2908 & Strawberry flavour mix, powder, with whole milk \\
\hline 2932 & Milk shake (fast food), strawberry \\
\hline 4711 & Milk, fluid, chocolate, partly skimmed, $1 \%$ M.F. \\
\hline 5268 & Beverage mix, carob flavour, powder, with $2 \%$ M.F. milk \\
\hline 5269 & Beverage mix, chocolate flavour, powder, with $2 \%$ M.F. milk \\
\hline 5273 & Malted milk, natural flavour, powder, with $2 \%$ M.F. milk \\
\hline
\end{tabular}


Table 3 (continued)

\begin{tabular}{|c|c|}
\hline Nutrient Survey System code & Canadian Nutrient File description \\
\hline 5275 & Malted milk, chocolate flavour, powder, with $2 \%$ M.F. milk \\
\hline 5276 & Strawberry flavour mix, powder, with $2 \%$ M.F. milk \\
\hline 5589 & Chocolate flavour drink, whey and milk-based \\
\hline 6636 & Hot chocolate, mix, powder, prepared with $2 \%$ milk \\
\hline 500024 & Chocolate flavour mix beverage, powder, milk added, NS as to type of milk \\
\hline 500025 & Chocolate flavour mix beverage, whole milk added \\
\hline 500026 & Chocolate, flavour mix beverage, powder, $1 \%$ milk added \\
\hline 500027 & Chocolate flavour mix beverage, skim milk added \\
\hline 500035 & Malted milk, natural flavour, enriched, powder, $2 \%$ milk added \\
\hline 500036 & Malted milk, chocolate, enriched, powder, milk added \\
\hline 500037 & Malted milk, NS as to flavour, enriched, powder, milk added \\
\hline 500038 & Eggnog, made with $2 \%$ milk \\
\hline 500039 & Milk shake, NS as to flavour or type \\
\hline 500040 & Milk shake, homemade or fountain-type, NS as to flavour \\
\hline 500041 & Milk shake with malt (malted milk with ice cream) \\
\hline 500042 & Milk shake, restaurant type, NS as to flavour (thick shake mix, milk added) \\
\hline 500043 & Milk-based fruit drink \\
\hline 500064 & Ice cream soda, flavours other than chocolate (root beer float) \\
\hline 500065 & Ice cream soda, chocolate (root beer float) \\
\hline 502759 & Chocolate flavour mix beverage, powder, $2 \%$ milk added \\
\hline 502760 & Chocolate syrup, $2 \%$ milk added \\
\hline 502770 & Milk, flavours other than chocolate, $2 \%$ milk-based (strawberry, vanilla, powder and syrup) \\
\hline 502783 & Milk shake, restaurant type, chocolate, thick \\
\hline 502784 & Milk shake, restaurant type, vanilla, thick \\
\hline 504172 & Milk shake, homemade or fountain-type, chocolate \\
\hline 504173 & Milk shake, homemade or fountain-type, flavours other than chocolate \\
\hline 504359 & Chocolate syrup, skim milk added \\
\hline 504695 & Chocolate syrup, $1 \%$ milk added \\
\hline 504696 & Chocolate syrup, whole milk added \\
\hline 504974 & Milk, chocolate, NFS \\
\hline 504976 & Chocolate syrup, milk added, NS as to type of milk \\
\hline 504977 & Milk, flavours other than chocolate, NFS (strawberry, vanilla, powder and syrup) \\
\hline 504978 & Milk, flavours other than chocolate, whole milk-based (strawberry, vanilla, powder and syrup) \\
\hline 504979 & Milk, flavours other than chocolate, $1 \%$ milk-based (strawberry, vanilla, powder and syrup) \\
\hline 504980 & Milk, flavours other than chocolate, skim milk-based (strawberry, vanilla, powder and syrup) \\
\hline \multicolumn{2}{|c|}{ Sugar-sweetened plant-based beverage (beverage type: sugary drink, sugar-sweetened beverage) } \\
\hline 4780 & Plant-based beverage, rice, enriched \\
\hline 5241 & Plant-based beverage, soy, original and vanilla, unenriched \\
\hline 5429 & Plant-based beverage, soy, unenriched, chocolate \\
\hline 6329 & Plant-based beverage, soy, enriched, chocolate \\
\hline 6331 & Plant-based beverage, soy, enriched, all flavours, low fat \\
\hline 6332 & Plant-based beverage, soy, enriched, all flavours, fat free \\
\hline 6666 & Plant-based beverage, soy, enriched, with omega- 3 fatty acids added \\
\hline 6720 & Plant-based beverage, soy, enriched, all flavours \\
\hline 6784 & Plant-based beverage, soy, enriched, all flavours, reduced fat \\
\hline 7225 & Plant-based beverage, almond, enriched, sweetened, vanilla flavoured \\
\hline 7226 & Plant-based beverage, almond, enriched, sweetened, chocolate flavoured \\
\hline 7478 & Plant-based beverage, coconut, enriched, sweetened, all flavours \\
\hline 7480 & Plant-based beverage, cashew, enriched, sweetened \\
\hline 7570 & Plant-based beverage, coconut, unenriched, sweetened, all flavours \\
\hline \multicolumn{2}{|c|}{ Sugar-sweetened smoothie (beverage type: sugary drink, sugar-sweetened beverage) } \\
\hline 504145 & Fruit smoothie drink, made with fruit or fruit juice only (no dairy products) \\
\hline 504171 & Milk fruit drink (smoothie) \\
\hline 504981 & Fruit smoothie drink, NFS \\
\hline
\end{tabular}


Table 3 (continued)

\begin{tabular}{|c|c|}
\hline Nutrient Survey System code & Canadian Nutrient File description \\
\hline \multicolumn{2}{|c|}{ Sugar-sweetened coffee (beverage type: sugary drink, sugar-sweetened beverage) } \\
\hline 2928 & Coffee, instant, sweetened, cappuccino flavour, powder, water added \\
\hline 2929 & Coffee, instant, sweetened, French flavour, powder, water added \\
\hline 2930 & Coffee, instant, sweetened, mocha flavour, powder, water added \\
\hline 502439 & Coffee, instant, pre-sweetened, no whitener, powder, water added \\
\hline 502440 & Coffee and cocoa (mocha), instant, with whitener, pre-sweetened, powder, water added \\
\hline 502441 & Coffee, regular, pre-sweetened with sugar, pre-lightened \\
\hline 504363 & Coffee, mocha, with whipped cream \\
\hline 504386 & Blended coffee beverage, regular coffee, sweetened, with whipped cream \\
\hline 504722 & Blended coffee beverage, decaffeinated coffee, sweetened \\
\hline 504729 & Blended coffee beverage, regular coffee, sweetened \\
\hline 504847 & Coffee, mocha, without whipped cream \\
\hline 505183 & Blended coffee beverage, decaffeinated coffee, sweetened, with whipped cream \\
\hline \multicolumn{2}{|c|}{ Sugar-sweetened tea (beverage type: sugary drink, sugar-sweetened beverage) } \\
\hline 2914 & Tea, instant, sweetened, lemon flavour, powder \\
\hline 2915 & Tea, instant, sweetened, lemon flavour, powder, water added \\
\hline 4908 & Tea, iced, lemon flavour, ready-to-drink \\
\hline 5291 & Tea, instant, sweetened, lemon flavour, powder, decaffeinated \\
\hline 6703 & Tea, chai latte, prepared with whole milk \\
\hline 502452 & Tea, NS as to type, pre-sweetened with sugar \\
\hline 502453 & Tea, NS as to type, sweetened, NS as to sweetener (lemon-flavoured) \\
\hline 502454 & Tea, NS as to type, sweetened, NS as to sweetener, decaffeinated \\
\hline 502456 & Tea, made from powdered instant, pre-sweetened with sugar (NS as to sweetener, iced tea) \\
\hline 504730 & Tea, chai latte \\
\hline \multicolumn{2}{|c|}{ Sugar-sweetened hot chocolate (beverage type: sugary drink, sugar-sweetened beverage) } \\
\hline 500028 & Hot chocolate, made from dry mix, water added \\
\hline 504779 & Hot chocolate, made from dry mix, milk added \\
\hline \multicolumn{2}{|c|}{ Sugar-sweetened yogurt beverage (beverage type: sugary drink, sugar-sweetened beverage) } \\
\hline 6993 & Yogourt beverage, fruit flavoured \\
\hline 6994 & Yogourt beverage, vanilla flavoured \\
\hline 7119 & Yogourt beverage, fruit flavoured, with added vitamin D \\
\hline 7120 & Yogourt beverage, vanilla flavoured, with added vitamin D \\
\hline \multicolumn{2}{|c|}{ Regular sports drink (beverage type: sugary drink, sugar-sweetened beverage) } \\
\hline 5962 & Sports drink, fruit flavour, ready-to-drink \\
\hline 5963 & Sports drink, lemon-lime flavour, ready-to-drink \\
\hline \multicolumn{2}{|c|}{ Regular flavoured water (beverage type: sugary drink, sugar-sweetened beverage) } \\
\hline 7185 & Vitamin water, all flavours, sweetened \\
\hline 7187 & Vitamin water, lemon/orange flavours, sweetened \\
\hline 7189 & Vitamin water, tropical citrus flavour, sweetened, with caffeine \\
\hline 7237 & Vitamin water, flavours not lemon/orange, sweetened \\
\hline \multicolumn{2}{|c|}{ Regular energy drink (beverage type: sugary drink, sugar-sweetened beverage) } \\
\hline 7173 & Energy drink, coffee flavours \\
\hline 7175 & Energy drink, various flavours \\
\hline 7176 & Energy drink, coffee flavours, light \\
\hline 7178 & Energy drink, with fruit juice \\
\hline 7179 & Energy drink, caffeine free \\
\hline 7180 & Energy drink, tea flavoured \\
\hline
\end{tabular}


Table 4 (supporting documentation for Fig. 1). Sex-specific prevalence (\%) of sugary drink consumption by beverage type and socioeconomic position in children/adolescents on a given day

\begin{tabular}{|c|c|c|c|c|c|c|c|}
\hline & \multirow[b]{2}{*}{$N$} & \multicolumn{2}{|l|}{ Sugary drinks } & \multicolumn{2}{|c|}{ Sugar-sweetened beverages } & \multicolumn{2}{|l|}{$100 \%$ Juice } \\
\hline & & $\begin{array}{l}\text { Prevalence } \\
(95 \% \mathrm{CI})\end{array}$ & $\begin{array}{l}\text { Prevalence } \\
\text { difference } \\
(95 \% \mathrm{CI})\end{array}$ & $\begin{array}{l}\text { Prevalence } \\
(95 \% \mathrm{CI}) \\
\end{array}$ & $\begin{array}{l}\begin{array}{l}\text { Prevalence } \\
\text { difference }\end{array} \\
(95 \% \mathrm{CI})\end{array}$ & $\begin{array}{l}\text { Prevalence } \\
(95 \% \mathrm{CI})\end{array}$ & $\begin{array}{l}\begin{array}{l}\text { Prevalence } \\
\text { difference }\end{array} \\
(95 \% \mathrm{CI})\end{array}$ \\
\hline \multicolumn{8}{|l|}{ Females (2-18 years) } \\
\hline Overall population & 3050 & $72(68,75)$ & & $52(49,56)$ & & $37(33,40)$ & \\
\hline \multicolumn{8}{|l|}{ Highest household education } \\
\hline Less than high school & 94 & $87(71,102)$ & $21(5,37)$ & $74(55,94)$ & $27(7,47)$ & $26(10,42)$ & $-10(-26,6)$ \\
\hline High school diploma & 471 & $76(69,83)$ & $11(2,19)$ & $56(47,65)$ & $9(-2,19)$ & $40(29,52)$ & $5(-7,17)$ \\
\hline $\begin{array}{l}\text { Credential below bachelor's } \\
\text { degree }\end{array}$ & 1205 & $77(71,82)$ & $11(4,19)$ & $55(50,61)$ & $8(0,16)$ & $37(32,42)$ & $2(-4,8)$ \\
\hline Bachelor's degree or above & 1280 & $66(61,70)$ & Ref & $47(42,53)$ & Ref & $36(31,40)$ & Ref \\
\hline \multicolumn{8}{|l|}{ Household food security status } \\
\hline Food insecure & 379 & $77(70,84)$ & $6(-2,14)$ & $57(48,66)$ & $5(-5,15)$ & $38(29,46)$ & $1(-7,10)$ \\
\hline Food secure & 2671 & $71(68,75)$ & Ref & $52(48,55)$ & Ref & $36(33,40)$ & Ref \\
\hline \multicolumn{8}{|l|}{ Household income quintile } \\
\hline Q1, lowest & 598 & $77(71,83)$ & $5(-5,15)$ & $53(45,60)$ & $1(-12,13)$ & $42(34,49)$ & $7(-5,18)$ \\
\hline Q2 & 577 & $69(61,78)$ & $-2(-15,10)$ & $49(42,56)$ & $-3(-16,9)$ & $36(29,43)$ & $1(-8,10)$ \\
\hline Q3 & 683 & $72(65,78)$ & $0(-10,10)$ & $54(47,60)$ & $1(-10,13)$ & $36(29,43)$ & $1(-9,12)$ \\
\hline Q4 & 629 & $69(62,76)$ & $-3(-12,6)$ & $54(47,62)$ & $2(-9,13)$ & $33(26,41)$ & $-1(-12,9)$ \\
\hline Q5, highest & 563 & $72(64,79)$ & Ref & $52(43,61)$ & Ref & $35(27,42)$ & Ref \\
\hline \multicolumn{8}{|l|}{ Males (2-18 years) } \\
\hline Overall population & 3064 & $78(75,80)$ & & $56(53,59)$ & & $42(38,45)$ & \\
\hline \multicolumn{8}{|l|}{ Highest household education } \\
\hline Less than high school & 96 & $76(55,97)$ & $0(-21,22)$ & $58(35,81)$ & $6(-17,28)$ & $39(18,61)$ & $-4(-26,18)$ \\
\hline High school diploma & 467 & $80(72,89)$ & $4(-8,17)$ & $63(53,72)$ & $10(-3,23)$ & $39(31,47)$ & $-4(-14,6)$ \\
\hline $\begin{array}{l}\text { Credential below bachelor's } \\
\text { degree }\end{array}$ & 1250 & $79(75,82)$ & $3(-3,9)$ & $57(53,61)$ & $5(-3,12)$ & $41(37,46)$ & $-2(-10,6)$ \\
\hline Bachelor's degree or above & 1251 & $76(70,81)$ & Ref & $52(47,58)$ & Ref & $43(37,49)$ & Ref \\
\hline \multicolumn{8}{|l|}{ Household food security status } \\
\hline Food insecure & 394 & $74(65,84)$ & $-4(-15,8)$ & $59(48,69)$ & $3(-9,15)$ & $34(26,42)$ & $-9(-18,0)$ \\
\hline Food secure & 2670 & $78(75,81)$ & Ref & $56(52,59)$ & Ref & $43(39,47)$ & Ref \\
\hline \multicolumn{8}{|l|}{ Household income quintile } \\
\hline Q1, lowest & 593 & $77(71,83)$ & $1(-8,10)$ & $60(53,66)$ & $5(-6,15)$ & $39(32,46)$ & $1(-10,12)$ \\
\hline Q2 & 581 & $77(70,83)$ & $0(-8,9)$ & $53(46,60)$ & $-2(-13,8)$ & $41(32,49)$ & $3(-8,13)$ \\
\hline Q3 & 719 & $82(77,86)$ & $5(-2,12)$ & $58(51,65)$ & $3(-8,14)$ & $46(38,53)$ & $7(-2,17)$ \\
\hline Q4 & 636 & $75(69,81)$ & $-2(-10,6)$ & $53(46,60)$ & $-3(-13,8)$ & $43(37,50)$ & $5(-5,15)$ \\
\hline Q5, highest & 535 & $76(71,82)$ & Ref & $55(47,63)$ & Ref & $38(30,46)$ & Ref \\
\hline
\end{tabular}

Data source: 2015 Canadian Community Health Survey-Nutrition. Children/adolescents include respondents aged 2-18 years (females: 3050; males: 3064). SEP indicators include highest household educational attainment, household food security status and household income quintiles. Prevalence difference (PD) represents the absolute difference in mean prevalence and associated 95\% confidence intervals (CI) across SEP (education, food security, income quintile). ' $N$ ' represents the number of respondents across sex/age/and SEP indicators 
Table 5 (supporting documentation for Fig. 2). Sex-specific prevalence (\%) of sugary drink consumption by beverage type and socioeconomic position in adults on a given day

\begin{tabular}{|c|c|c|c|c|c|c|c|}
\hline & \multirow{3}{*}{$N$} & \multicolumn{2}{|c|}{ Sugary drinks } & \multicolumn{2}{|c|}{ Sugar-sweetened beverages } & \multicolumn{2}{|l|}{$100 \%$ Juice } \\
\hline & & Prevalence & $\begin{array}{l}\text { Prevalence } \\
\text { difference }\end{array}$ & Prevalence & $\begin{array}{l}\text { Prevalence } \\
\text { difference }\end{array}$ & Prevalence & $\begin{array}{l}\text { Prevalence } \\
\text { difference }\end{array}$ \\
\hline & & $(95 \% \mathrm{CI})$ & $(95 \% \mathrm{CI})$ & $(95 \% \mathrm{CI})$ & $(95 \% \mathrm{CI})$ & $(95 \% \mathrm{CI})$ & $(95 \% \mathrm{CI})$ \\
\hline \multicolumn{8}{|l|}{ Females ( $\geq 19$ years) } \\
\hline Overall population & 7219 & $50(47,52)$ & & $35(33,38)$ & & $22(20,24)$ & \\
\hline \multicolumn{8}{|l|}{ Highest household education } \\
\hline Less than high school & 888 & $48(41,54)$ & $-2(-9,5)$ & $28(21,36)$ & $-6(-12,0)$ & $26(19,33)$ & $2(-5,9)$ \\
\hline High school diploma & 1462 & $52(46,59)$ & $3(-3,8)$ & $40(35,44)$ & $5(-1,11)$ & $17(10,24)$ & $-7(-15,1)$ \\
\hline Credential below bachelor's degree & 2614 & $49(45,52)$ & $-1(-7,5)$ & $36(32,39)$ & $1(-4,6)$ & $21(18,24)$ & $-3(-7,1)$ \\
\hline Bachelor's degree or above & 2255 & $50(46,54)$ & Ref & $34(30,39)$ & Ref & $24(21,27)$ & Ref \\
\hline \multicolumn{8}{|l|}{ Household food security status } \\
\hline Food insecure & 742 & $59(51,66)$ & $10(1,19)$ & $48(38,59)$ & $14(2,27)$ & $19(13,25)$ & $-3(-9,3)$ \\
\hline Food secure & 6477 & $49(46,52)$ & Ref & $34(31,37)$ & Ref & $22(20,24)$ & Ref \\
\hline \multicolumn{8}{|l|}{ Household income quintile } \\
\hline Q1, lowest & 1719 & $53(49,57)$ & $11(1,20)$ & $38(33,43)$ & $10(-1,21)$ & $24(20,29)$ & $5(-1,10)$ \\
\hline Q2 & 1603 & $48(43,53)$ & $5(-3,13)$ & $34(29,39)$ & $6(-5,17)$ & $19(16,23)$ & $0(-8,7)$ \\
\hline Q3 & 1495 & $52(46,57)$ & $9(-2,20)$ & $37(32,41)$ & $8(-6,23)$ & $23(19,27)$ & $3(-3,9)$ \\
\hline Q4 & 1213 & $53(48,58)$ & $10(2,19)$ & $39(34,45)$ & $11(-4,26)$ & $22(15,29)$ & $2(-9,13)$ \\
\hline Q5, highest & 1189 & $42(34,51)$ & Ref & $28(16,40)$ & Ref & $20(15,25)$ & Ref \\
\hline \multicolumn{8}{|l|}{ Males ( $\geq 19$ years) } \\
\hline Overall population & 6409 & $58(55,60)$ & & $44(41,46)$ & & $25(23,27)$ & \\
\hline \multicolumn{8}{|l|}{ Highest household education } \\
\hline Less than high school & 670 & $52(45,59)$ & $-4(-12,3)$ & $38(29,48)$ & $-1(-10,7)$ & $21(13,29)$ & $-6(-16,3)$ \\
\hline High school diploma & 1268 & $58(52,64)$ & $2(-7,11)$ & $47(42,52)$ & $7(0,15)$ & $22(17,27)$ & $-6(-12,1)$ \\
\hline Credential below bachelor's degree & 2360 & $60(54,66)$ & $3(-6,12)$ & $47(41,53)$ & $8(-2,17)$ & $24(20,29)$ & $-3(-9,3)$ \\
\hline Bachelor's degree or above & 2111 & $56(52,61)$ & Ref & $40(35,44)$ & Ref & $27(24,31)$ & Ref \\
\hline \multicolumn{8}{|l|}{ Household food security status } \\
\hline Food insecure & 541 & $60(47,72)$ & $2(-12,16)$ & $51(42,60)$ & $9(-1,19)$ & $17(9,24)$ & $-9(-18,0)$ \\
\hline Food secure & 5868 & $57(55,60)$ & Ref & $43(40,45)$ & Ref & $26(23,28)$ & Ref \\
\hline \multicolumn{8}{|l|}{ Household income quintile } \\
\hline Q1, lowest & 1125 & $59(54,64)$ & $2(-5,10)$ & $42(35,49)$ & $-2(-18,14)$ & $25(17,33)$ & $-2(-11,7)$ \\
\hline Q2 & 1283 & $59(54,64)$ & $2(-7,10)$ & $47(42,52)$ & $4(-7,14)$ & $23(19,28)$ & $-4(-10,3)$ \\
\hline Q3 & 1390 & $57(52,61)$ & $-1(-8,7)$ & $41(37,46)$ & $-2(-13,8)$ & $26(22,29)$ & $-1(-7,4)$ \\
\hline Q4 & 1200 & $56(50,62)$ & $\begin{array}{c}-1(-12 \\
10)\end{array}$ & $44(38,49)$ & $0(-13,13)$ & $24(19,29)$ & $-3(-10,3)$ \\
\hline Q5, highest & 1411 & $57(50,64)$ & Ref & $44(33,54)$ & Ref & $27(23,31)$ & Ref \\
\hline
\end{tabular}

Data source: 2015 Canadian Community Health Survey-Nutrition. Adults include respondents aged 19 years and older (females: 7219 ; males: 6409). SEP indicators include highest household educational attainment, household food security status and household income quintiles. Prevalence difference (PD) represents the absolute difference in mean prevalence and associated 95\% confidence intervals (CI) across SEP (education, food security, income quintile). ' $N$ ' represents the number of respondents across sex/age/and SEP indicators 
Table 6 Sex-specific prevalence ratios of sugary drink consumption by beverage type and socioeconomic position in children/adolescents on a given day

$\begin{array}{llll} & \text { Sugary drinks } & \text { Sugar-sweetened beverages } & 100 \% \text { Juice } \\ \text { Prevalence ratio } & \text { Prevalence ratio } & \text { Prevalence ratio } \\ (95 \% \mathrm{CI}) & (95 \% \mathrm{CI}) & (95 \% \mathrm{CI})\end{array}$

\begin{tabular}{|c|c|c|c|c|}
\hline \multicolumn{5}{|l|}{ Females (2-18 years) } \\
\hline \multicolumn{5}{|l|}{ Highest household education } \\
\hline Less than high school & 94 & $1.32(1.09,1.59)$ & $1.57(1.18,2.08)$ & $0.73(0.39,1.35)$ \\
\hline High school diploma & 471 & $1.16(1.04,1.30)$ & $1.18(0.97,1.44)$ & $1.14(0.83,1.55)$ \\
\hline Credential below bachelor's degree & 1205 & $1.17(1.06,1.30)$ & $1.17(1.00,1.37)$ & $1.05(0.88,1.25)$ \\
\hline Bachelor's degree or above & 1280 & Ref & Ref & Ref \\
\hline \multicolumn{5}{|l|}{ Household food security status } \\
\hline Food insecure & 379 & $1.08(0.98,1.20)$ & $1.10(0.92,1.31)$ & $1.04(0.82,1.31)$ \\
\hline Food secure & 2671 & Ref & Ref & Ref \\
\hline \multicolumn{5}{|l|}{ Household income quintile } \\
\hline Q1, lowest & 598 & $1.07(0.94,1.23)$ & $1.01(0.79,1.29)$ & $1.20(0.89,1.62)$ \\
\hline Q2 & 577 & $0.97(0.81,1.15)$ & $0.93(0.73,1.20)$ & $1.04(0.80,1.34)$ \\
\hline Q3 & 683 & $1.00(0.87,1.14)$ & $1.03(0.83,1.27)$ & $1.04(0.78,1.39)$ \\
\hline Q4 & 629 & $0.96(0.84,1.09)$ & $1.04(0.85,1.28)$ & $0.96(0.70,1.32)$ \\
\hline Q5, highest & 563 & Ref & Ref & Ref \\
\hline \multicolumn{5}{|l|}{ Males (2-18 years) } \\
\hline \multicolumn{5}{|l|}{ Highest household education } \\
\hline Less than high school & 96 & $1.01(0.76,1.34)$ & $1.11(0.75,1.64)$ & $0.91(0.52,1.59)$ \\
\hline High school diploma & 467 & $1.06(0.90,1.23)$ & $1.19(0.96,1.48)$ & $0.91(0.71,1.15)$ \\
\hline Credential below bachelor's degree & 1250 & $1.04(0.96,1.12)$ & $1.09(0.95,1.24)$ & $0.95(0.79,1.14)$ \\
\hline Bachelor's degree or above & 1251 & Ref & Ref & Ref \\
\hline \multicolumn{5}{|l|}{ Household food security status } \\
\hline Food insecure & 394 & $0.95(0.82,1.11)$ & $1.05(0.86,1.29)$ & $0.79(0.61,1.02)$ \\
\hline Food secure & 2670 & Ref & Ref & Ref \\
\hline \multicolumn{5}{|l|}{ Household income quintile } \\
\hline Q1, lowest & 593 & $1.01(0.90,1.13)$ & $1.09(0.90,1.31)$ & $1.03(0.78,1.36)$ \\
\hline Q2 & 581 & $1.00(0.90,1.12)$ & $0.96(0.79,1.17)$ & $1.07(0.82,1.40)$ \\
\hline Q3 & 719 & $1.07(0.97,1.17)$ & $1.05(0.87,1.27)$ & $1.19(0.94,1.50)$ \\
\hline Q4 & 636 & $0.98(0.88,1.09)$ & $0.95(0.79,1.15)$ & $1.13(0.88,1.45)$ \\
\hline Q5, highest & 535 & Ref & Ref & Ref \\
\hline
\end{tabular}

Data source: 2015 Canadian Community Health Survey-Nutrition. Children/adolescents include respondents aged 2-18 years (females: 3050; males: 3064). SEP indicators include highest household educational attainment, household food security status and household income quintiles. Prevalence ratio (PR) represents relative prevalence of consuming on a given day and associated $95 \%$ confidence intervals (CI) across SEP (education, food security, income quintile). ' $N$ ' represents the number of respondents across sex/age/and SEP indicators 
Table 7 Sex-specific prevalence ratios of sugary drink consumption by beverage type and socioeconomic position in adults on a given day

$\begin{array}{llll}N & \text { Sugary drinks } & \text { Sugar-sweetened beverages } & 100 \% \text { Juice } \\ \text { Prevalence ratio } & \text { Prevalence ratio } & \text { Prevalence ratio } \\ (95 \% \mathrm{CI}) & (95 \% \mathrm{CI}) & (95 \% \mathrm{CI})\end{array}$

\begin{tabular}{|c|c|c|}
\hline \multicolumn{3}{|l|}{ Females ( $\geq 19$ years) } \\
\hline \multicolumn{3}{|l|}{ Highest household education } \\
\hline Less than high school & 888 & $0.96(0.83,1.10)$ \\
\hline High school diploma & 1462 & $1.05(0.94,1.18)$ \\
\hline Credential below bachelor's degree & 2614 & $0.97(0.86,1.10)$ \\
\hline Bachelor's degree or above & 2255 & Ref \\
\hline \multicolumn{3}{|l|}{ Household food security status } \\
\hline Food insecure & 742 & $1.21(1.03,1.41)$ \\
\hline Food secure & 6477 & Ref \\
\hline \multicolumn{3}{|l|}{ Household income quintile } \\
\hline Q1, lowest & 1719 & $1.25(1.00,1.56)$ \\
\hline Q2 & 1603 & $1.13(0.94,1.36)$ \\
\hline Q3 & 1495 & $1.22(0.95,1.56)$ \\
\hline Q4 & 1213 & $1.24(1.03,1.50)$ \\
\hline Q5, highest & 1189 & Ref \\
\hline \multicolumn{3}{|l|}{ Males ( $\geq 19$ years) } \\
\hline \multicolumn{3}{|l|}{ Highest household education } \\
\hline Less than high school & 670 & $0.92(0.79,1.07)$ \\
\hline High school diploma & 1268 & $1.03(0.88,1.20)$ \\
\hline Credential below bachelor's degree & 2360 & $1.05(0.90,1.24)$ \\
\hline Bachelor's degree or above & 2111 & Ref \\
\hline \multicolumn{3}{|l|}{ Household food security status } \\
\hline Food insecure & 541 & $1.04(0.82,1.32)$ \\
\hline Food secure & 5868 & Ref \\
\hline \multicolumn{3}{|l|}{ Household income quintile } \\
\hline Q1, lowest & 1125 & $1.04(0.91,1.19)$ \\
\hline Q2 & 1283 & $1.03(0.89,1.19)$ \\
\hline Q3 & 1390 & $0.99(0.87,1.13)$ \\
\hline Q4 & 1200 & $0.98(0.81,1.19)$ \\
\hline Q5, highest & 1411 & Ref \\
\hline
\end{tabular}

$\begin{array}{ll}0.82(0.66,1.02) & 1.09(0.82,1.44) \\ 1.15(0.98,1.36) & 0.72(0.46,1.13) \\ 1.03(0.88,1.20) & 0.88(0.73,1.04) \\ \operatorname{Ref} & \operatorname{Ref} \\ & \\ 1.42(1.07,1.88) & 0.85(0.62,1.18) \\ \operatorname{Ref} & \operatorname{Ref} \\ & \\ 1.35(0.90,2.01) & 1.23(0.95,1.60) \\ 1.21(0.81,1.79) & 0.98(0.68,1.40) \\ 1.30(0.80,2.12) & 1.15(0.87,1.53) \\ 1.39(0.84,2.30) & 1.09(0.65,1.83) \\ \operatorname{Ref} & \operatorname{Ref}\end{array}$

$0.96(0.77,1.21) \quad 0.78(0.51,1.19)$

$1.18(1.00,1.41) \quad 0.80(0.61,1.05)$

$1.19(0.97,1.47) \quad 0.89(0.7,1.12)$

Ref Ref

$1.20(0.98,1.46) \quad 0.64(0.38,1.08)$

Ref Ref

$0.96(0.66,1.40) \quad 0.93(0.64,1.34)$

$1.08(0.85,1.38) \quad 0.86(0.67,1.12)$

$0.94(0.74,1.21) \quad 0.95(0.76,1.18)$

$1.00(0.74,1.36) \quad 0.88(0.67,1.15)$

Ref Ref

Data source: 2015 Canadian Community Health Survey-Nutrition. Adults include respondents aged 19 years and older (females: 7219; males: 6409). SEP indicators include highest household educational attainment, household food security status and household income quintiles. Prevalence ratio (PR) represents relative prevalence of consuming on a given day and associated $95 \%$ confidence intervals (CI) across SEP (education, food security, income quintile). ' $N$ ' represents the number of respondents across sex/age/and SEP indicators

\section{Appendix 2. Accounting for energy misreporting in dietary assessments}

We included energy misreporting as a sensitivity analysis to account for confounding related to systematic error in self-reported dietary assessments. Energy misreporting was measured based on the ratio of energy intake (EI) to total estimated energy requirement (EER). Children under 12 years were classified as under-reporters (EI:EER $<74 \%$ ); over-reporters (EI:EER $>135 \%$ ) and plausible reporters
(74\% $\leq$ EI:EER $\leq 135 \%$ ) (Garriguet, 2009; Jessri et al., 2016a; Jessri et al., 2016b; McCrory et al., 2002; National Academy Press, 2002). Individuals 12 years and over were classified using appropriate cutoff ratios for this age group: under-reporters (EI:EER $<70 \%$ ), plausible reporters (70\% $\leq$ EI:EER $\leq 142 \%)$; over-reporters (EI:EER $>142 \%)$. Estimated energy requirements were determined using the National Academies of Sciences, Engineering and Medicine (NASEM) factorial equations, fully described elsewhere (Nomaguchi et al., 2017). The NASEM equations 
incorporate an individual's age, sex, physical activity level and body mass index (BMI) (National Academy Press, 2002). For individuals aged 2-17, BMI classification was based on sex- and age-specific cutoff points defined by the WHO (Health Canada, 2017). BMI was calculated using measured height and weight where possible, but when not available, was estimated using validated equations to correct for self-reported height and weight (National Academy Press, 2002; Shields et al., 2011). For individuals with missing BMI, USDA EER equations were applied based on respondent's age, sex and reported physical activity (Brouillard et al., 2019; National Academy Press, 2002). We grouped respondents with missing information to estimate misreporting, including underweight respondents who are not included in estimating equations, as 'unclassified'. Results from the misreporting adjusted analyses were consistent with the primary unadjusted results and are available upon request.

Acknowledgements We thank Salma Hack for providing nutritionrelated analytical support using the Canadian Community Health Survey-Nutrition 2015.

Author contributions BTS, EH and DGM contributed to the conception and design of this work. BTS and DGM acquired funding for this work. CW contributed to the formal analysis. CW and BTS contributed to the interpretation of data and results; CW, BTS, EH, LNA, DH, JA, MJ, EH, HM, LCR, MRL, YL and DGM contributed to this study's methodology. BTS led this work's supervision. CW and BTS contributed to the writing of the original draft. CW, BTS, EH, LNA, DH, JA, MJ, EH, HM, LCR, MRL, YL and DGM contributed to review and editing of this work. All authors read and approved the final manuscript.

Funding This research was funded by the Canadian Institutes of Health Research (Project Grant \#391602).

Data availability The data that support the findings of this study are available from Statistics Canada upon request (https://www150.statc an.gc.ca/n1/en/catalogue/82M0024X).

Code availability Code is available through accessing a public repository found here: https://github.com/BtsmithPHO/Sugary-drinks-descr iptive

\section{Declarations}

Ethics approval This study was approved by the Ethics Review Board at Public Health Ontario (Protocol Code: 2018-046.01 and Date of Approval: 2018-Sep-11).

Consent to participate Not applicable.

Consent for publication Not applicable.

Conflict of interest The authors declare no competing interests.
Open Access This article is licensed under a Creative Commons Attribution 4.0 International License, which permits use, sharing, adaptation, distribution and reproduction in any medium or format, as long as you give appropriate credit to the original author(s) and the source, provide a link to the Creative Commons licence, and indicate if changes were made. The images or other third party material in this article are included in the article's Creative Commons licence, unless indicated otherwise in a credit line to the material. If material is not included in the article's Creative Commons licence and your intended use is not permitted by statutory regulation or exceeds the permitted use, you will need to obtain permission directly from the copyright holder. To view a copy of this licence, visit http://creativecommons.org/licenses/by/4.0/.

\section{References}

Braveman, P. A., Cubbin, C., Egerter, S., Chideya, S., Marchi, K. S., Metzler, M., \& Posner, S. (2005). Socioeconomic status in health research: one size does not fit all. JAMA, 204(22), 2879-2888.

Briggs, A. D., Mytton, O. T., Kehlbacher, A., Tiffin, R., Rayner, M., \& Scarborough, P. (2013). Overall and income specific effect on prevalence of overweight and obesity of $20 \%$ sugar sweetened drink tax in UK: Econometric and comparative risk assessment modelling study. BMJ, 347, f6189. https://doi.org/10.1136/bmj. f6189

Brouillard, A. M., Kraja, A. T., \& Rich, M. W. (2019). Trends in dietary sodium intake in the United States and the impact of USDA Guidelines: NHANES 1999-2016. The American Journal of Medicine, 132(10), 1199-1206.e5. https://doi.org/10.1016/j.amjmed. 2019.04.040

Coady, S. (2021, May 31). 2021 Budget Speech. First Session of the 50th General Assembly of the House of Assembly, Newfoundland and Labrador. Retrieved June 15, 2021, from https://www.gov.nl. ca/budget/2021/wp-content/uploads/sites/5/budget-speech-2021. pdf

Conroy, S., \& Murray, E. J. (2020). Let the question determine the methods: Descriptive epidemiology done right. British Journal of Cancer, 123(9), 1351-1352. https://doi.org/10.1038/ s41416-020-1019-z

Czoli, C. D., Jones, A. C., \& Hammond, D. (2019). Trends in sugary drinks in Canada, 2004 to 2015: A comparison of market sales and dietary intake data. Public Health Nutrition, 1-6. https://doi. org/10.1017/S1368980019001654

Darmon, N., \& Drewnowski, A. (2015). Contribution of food prices and diet cost to socioeconomic disparities in diet quality and health: A systematic review and analysis. Nutrition Reviews, 73(10), 643-660. https://doi.org/10.1093/nutrit/nuv027

Drewnowski, A., \& Rehm, C. D. (2015). Socioeconomic gradient in consumption of whole fruit and $100 \%$ fruit juice among US children and adults. Nutr J, 14(3). https://doi.org/10.1186/ 1475-2891-14-3

Garriguet, D. (2009). Diet quality in Canada (No. 82-003-X). Statistics Canada.

Garriguet, D. (2018). Accounting for misreporting when comparing energy intake across time in Canada. Statistics Canada.

Garriguet, D. (2019). Changes in beverage consumption in Canada (Health Reports, pp. 20-30). Statistics Canada.

Global Burden of Disease. (2018). Global, regional, and national comparative risk assessment of 84 behavioural, environmental and occupational, and metabolic risks or clusters of risks for 195 countries and territories, 1990-2017: A systematic analysis for the 
Global Burden of Disease Study 2017. Lancet, 392, 1923-1994. https://doi.org/10.1016/S0140-6736(18)32225-6

Han, E., \& Powell, L. M. (2013). Consumption patterns of sugar-sweetened beverages in the United States. Journal of the Academy of Nutrition and Dietetics, 113(1), 43-53. https://doi.org/10.1016/j. jand.2012.09.016

Health Canada. (2017). Reference Guide to Understanding and Using the Data 2015 Canadian Community Health Survey-Nutrition. Health Canada.

Health Canada. (2019a). Canada's dietary guidelines for health professionals and policy makers. Retrieved May 5, 2021, from http:// epe.lac-bac.gc.ca/100/201/301/weekly_acquisitions_list-ef/2019/ 19-04/publications.gc.ca/collections/collection_2019/sc-hc/H164231-2019-eng.pdf

Health Canada. (2019b). Canada's food guide: Healthy eating recommendations.

Imamura, F., O’Connor, L., Ye, Z., Mursu, J., Hayashino, Y., Bhupathiraju, S. N., \& Forouhi, N. G. (2015). Consumption of sugar sweetened beverages, artificially sweetened beverages, and fruit juice and incidence of type 2 diabetes: Systematic review, metaanalysis, and estimation of population attributable fraction. $B M J$, h3576. https://doi.org/10.1136/bmj.h3576

Jessri, M., Lou, W. Y., \& L'Abbe, M. R. (2016a). Evaluation of different methods to handle misreporting in obesity research: Evidence from the Canadian national nutrition survey. British Journal of Nutrition, 115(1), 147-159. https://doi.org/10.1017/S000711451 5004237

Jessri, M., Nishi, S. K., \& L'Abbe, M. R. (2016b). Assessing the nutritional quality of diets of Canadian children and adolescents using the 2014 Health Canada Surveillance Tool Tier System. BMC Public Health, 16, 381. https://doi.org/10.1186/ s12889-016-3038-5

Johnson, J. L., Greaves, L., \& Repta, R. (2009). Better science with sex and gender: Facilitating the use of a sex and gender-based analysis in health research. International Journal for Equity in Health, 8(1), 14. https://doi.org/10.1186/1475-9276-8-14

Jones, A. C., Kirkpatrick, S. I., \& Hammond, D. (2019). Beverage consumption and energy intake among Canadians: Analyses of 2004 and 2015 national dietary intake data. Nutrition Journal, 18(1), 60. https://doi.org/10.1186/s12937-019-0488-5

Kao, K.-E., Jones, A. C., Ohinmaa, A., \& Paulden, M. (2020). The health and financial impacts of a sugary drink tax across different income groups in Canada. Economics \& Human Biology, 38, 100869. https://doi.org/10.1016/j.ehb.2020.100869

Kirkpatrick, S. I., Dodd, K. W., Parsons, R., Ng, C., Garriguet, D., \& Tarasuk, V. (2015). Household food insecurity is a stronger marker of adequacy of nutrient intakes among Canadian compared to American youth and adults. Journal of Nutrition, 145(7), 1596-1603. https://doi.org/10.3945/jn.114.208579

Kirkpatrick, S. I., Raffoul, A., Lee, K. M., \& Jones, A. C. (2019). Top dietary sources of energy, sodium, sugars, and saturated fats among Canadians: Insights from the 2015 Canadian Community Health Survey. Applied Physiology, Nutrition and Metabolism, 44(6), 650-658. https://doi.org/10.1139/apnm-2018-0532

Krieger, J., Bleich, S. N., Scarmo, S., \& Ng, S. W. (2021). Sugarsweetened beverage reduction policies: Progress and promise. Annual Review of Public Health, 42(1), 439-461. https://doi.org/ 10.1146/annurev-publhealth-090419-103005

Lal, A., Mantilla-Herrera, A. M., Veerman, L., Backholer, K., Sacks, G., Moodie, M., Siahpush, M., Carter, R., \& Peeters, A. (2017). Modelled health benefits of a sugar-sweetened beverage tax across different socioeconomic groups in Australia: A cost-effectiveness and equity analysis. PLoS Medicine, 14, e1002326. https://doi.org/ 10.1371/journal.pmed.1002326
Langlois, K., Garriguet, D., Gonzalez, A., Sinclair, S., \& Colapinto, C. K. (2019). Change in total sugars consumption among Canadian children and adults (Catalogue no. 82-003-X). Statistics Canada.

Liu, S., Munasinghe, L. L., Ohinmaa, A., \& Veugelers, P. J. (2020). Added, free and total sugar content and consumption of foods and beverages in Canada. https://doi.org/10.25318/82-003-X2020 01000002-ENG

Lumley, T., Diehr, P., Emerson, S., \& Chen, L. (2002). The importance of the normality assumption in large public health data sets. Annual Review of Public Health, 23(1), 151-169. https://doi.org/ 10.1146/annurev.publhealth.23.100901.140546

Makarem, N., Bandera, E. V., Nicholson, J. M., \& Parekh, N. (2018). Consumption of sugars, sugary foods, and sugary beverages in relation to cancer risk: A systematic review of longitudinal studies. Annual Review of Nutrition, 38, 17-39. https://doi.org/10. 1146/annurev-nutr-082117051805

Malik, V. S., Pan, A., Willett, W. C., \& Hu, F. B. (2013). Sugar-sweetened beverages and weight gain in children and adults: A systematic review and meta-analysis. American Journal of Clinical Nutrition, 98(4), 1084-1102. https://doi.org/10.3945/ajcn.113. 058362

McCrory, M. A., McCrory, M. A., Hajduk, C. L., \& Roberts, S. B. (2002). Procedures for screening out inaccurate reports of dietary energy intake. Public Health Nutrition, 5(6A), 873-882. https:// doi.org/10.1079/PHN2002387

National Academy Press. (2002). Institute of Medicine. Dietary reference intakes for energy, carbohydrate, fiber, fat, fatty acids, cholesterol, protein and amino acids. National Academy Press.

Nomaguchi, T., Cunich, M., Zapata-Diomedi, B., \& Veerman, J. L. (2017). The impact on productivity of a hypothetical tax on sugarsweetened beverages. Health Policy, 121, 715-725. https://doi. org/10.1016/j.healthpol.2017.04.001

Popkin, B. M., \& Ng, S. W. (2021). Sugar-sweetened beverage taxes: Lessons to date and the future of taxation. PLoS Medicine, 18(1), e1003412. https://doi.org/10.1371/journal.pmed.1003412

Shields, M., Gorber, S. C., Ian Janssen, I., \& Tremblay, M. S. (2011). Bias in self-reported estimates of obesity in Canadian health surveys: An update on correction equations for adults (Health Reports). Statistics Canada.

Statistics Canada. (2018). 2015 Canadian Community Health Survey (CCHS) - Nutrition User Guide. Statistics Canada.

Tooze, J. A., Midthune, D., Dodd, K. W., Freedman, L. S., KrebsSmith, S. M., Subar, A. F., Guenther, P. M., Carroll, R. J., \& Kipnis, V. (2006). A new statistical method for estimating the usual intake of episodically consumed foods with application to their distribution. Journal of the American Dietetic Association, 106(10), 1575-1587. https://doi.org/10.1016/j.jada.2006.07.003

von Philipsborn, P., Stratil, J. M., Burns, J., Busert, L. K., Pfadenhauer, L. M., Polus, S., Holzapfel, C., Hauner, H., \& Rehfuess, E. (2019). Environmental interventions to reduce the consumption of sugar-sweetened beverages and their effects on health. Cochrane Database Syst Rev, 6, CD012292. https://doi.org/10.1002/14651 858.CD012292.pub2

Wasserstein, R. L., \& Lazar, N. A. (2016). The ASA statement on p-values: Context, process, and purpose. The American Statistician, 70(2), 129-133. https://doi.org/10.1080/00031305.2016.1154108

World Health Organization. (2015). Guideline: Sugars intake for adults and children. World Health Organization.

Zou, G. (2004). A modified Poisson regression approach to prospective studies with binary data. American Journal of Epidemiology, 159(7), 702-706. https://doi.org/10.1093/aje/kwh090

Publisher's note Springer Nature remains neutral with regard to jurisdictional claims in published maps and institutional affiliations. 


\section{Authors and Affiliations}

\section{Christine Warren ${ }^{1}$ • Erin Hobin 1,2,3 . Douglas G. Manuel 4,5,6,7,8 Laura N. Anderson $^{9,10}$ • David Hammond ${ }^{11}$. Mahsa Jessri ${ }^{12}$. JoAnne Arcand ${ }^{13} \cdot$ Mary L'Abbé $^{2} \cdot$ Ye Li $^{1,3} \cdot$ Laura C. Rosella 3,5,14,15,16 $\cdot$ Heather Manson ${ }^{3}$. Brendan T. Smith ${ }^{1,3}$}

Brendan T. Smith brendan.smith@oahpp.ca

1 Public Health Ontario, 480 University Avenue, Suite 300, Toronto, ON M5G 1V2, Canada

2 Department of Nutritional Sciences, University of Toronto, Toronto, ON, Canada

3 Dalla Lana School of Public Health, University of Toronto, Toronto, ON, Canada

4 Clinical Epidemiology, Ottawa Hospital Research Institute, Ottawa, ON, Canada

5 Institute for Clinical Evaluative Sciences - Central Site, Toronto, ON, Canada

6 Health Analysis Division, Statistics Canada, Ottawa, ON, Canada

7 Department of Family Medicine, and School of Epidemiology and Public Health, University of Ottawa, Ottawa, ON, Canada
8 Bruyère Research Institute, Ottawa, $\mathrm{ON}$, Canada

9 Department of Health Research Methods, Evidence, and Impact, McMaster University, Hamilton, ON, Canada

10 Child Health Evaluative Sciences, SickKids Research Institute, Toronto, ON, Canada

11 School of Public Health and Health Systems, University of Waterloo, Waterloo, ON, Canada

12 Food, Nutrition and Health Program, University of British Columbia, Vancouver, BC, Canada

13 Faculty of Health Sciences, Ontario Tech University, Oshawa, ON, Canada

14 Institute for Better Health, Trillium Health Partners, Mississauga, ON, Canada

15 Vector Institute, Toronto, ON, Canada

16 Temerty Faculty of Medicine, Toronto, ON, Canada 